\title{
Tissue distribution and transcriptional regulation of CCN5 in the heart after myocardial infarction
}

\author{
Sima Zolfaghari ${ }^{1,2}$. Ole Jørgen Kaasbøll ${ }^{1}$ M. Shakil Ahmed ${ }^{1} \cdot$ Fabian A. Line $^{1,2} \cdot$ Else Marie V. Hagelin ${ }^{1}$. \\ Vivi T. Monsen ${ }^{1,2} \cdot$ Håvard Attramadal $^{1,2} \mathbb{D}$
}

Received: 9 August 2021 / Accepted: 11 November 2021 / Published online: 1 December 2021

(c) The Author(s) 2021

\begin{abstract}
CCN5 is a divergent member of the cellular communication network factor $(\mathrm{CCN})$ family in that it lacks the carboxyl terminal cystine knot domain common to the other CCN family members. CCN5 has been reported to antagonize the profibrotic actions of CCN2 and to inhibit myocardial collagen deposition and fibrosis in chronic pressure overload of the heart. However, what mechanisms that regulate CCN5 activity in the heart remain unknown. Recombinant, replication defective adenovirus encoding firefly luciferase under control of the human CCN5 promoter was prepared and used to investigate what mechanisms regulate CCN5 transcription in relevant cells. Tissue distribution of CCN5 in hearts from healthy mice and from mice subjected to myocardial infarction was investigated. Contrary to the profibrotic immediate early gene CCN2, we find that CCN5 is induced in the late proliferation and maturation phases of scar healing. CCN5 was identified principally in endothelial cells, fibroblasts, smooth muscle cells, and macrophages. Our data show that CCN5 gene transcription and protein levels are induced by catecholamines via $\beta_{2}$-adrenergic receptors. Myocardial induction of CCN5 was further confirmed in isoproterenol-infused mice. We also find that CCN5 transcription is repressed by TNF- $\alpha$, an inflammatory mediator highly elevated in early phases of wound healing following myocardial infarction. In conclusion, CCN5 predominates in endothelial cells, fibroblasts, and macrophages of the differentiating scar tissue and its transcription is conversely regulated by $\beta_{2}$-adrenergic agonists and TNF- $\alpha$.
\end{abstract}

Keywords $\beta_{2}$-Adrenergic receptor $\cdot$ Catecholamines $\cdot \mathrm{CCN} 5 \cdot \mathrm{CCN} 2 \cdot$ Myocardial infarction $\cdot$ Primary cardiac fibroblasts

$\begin{array}{ll}\text { Abbreviations } \\ \text { AR } & \text { Adrenergic receptor } \\ \text { CCN } & \text { Cellular communication network factor } \\ \text { cFB } & \text { Cardiac fibroblast } \\ \text { ChIP } & \text { Chromatin immunoprecipitation } \\ \text { CRE } & \text { cAMP response element } \\ \text { CT } & \text { C-terminal } \\ \text { CTGF } & \text { Connective tissue growth factor } \\ \text { DMEM } & \text { Dulbecco's modified Eagle's medium } \\ \text { EBM } & \text { Endothelial cell basal medium } \\ \text { ECM } & \text { Extracellular matrix } \\ \text { EndMT } & \text { Endothelial-mesenchymal transition }\end{array}$

Håvard Attramadal

havard.attramadal@medisin.uio.no

1 Institute for Surgical Research, Oslo University Hospital, Rm. A3.1056, Sognsvannsveien 20, Nydalen, P.O. Box 4950, 0424 Oslo, Norway

2 Institute of Clinical Medicine, University of Oslo, Oslo, Norway

$\begin{array}{ll}\text { EPACs } & \text { Exchange proteins activated by cAMP } \\ \text { FBS } & \text { Fetal bovine serum } \\ \text { FLUC } & \text { Firefly luciferase } \\ \text { GRE } & \text { Glucocorticoid response element } \\ \text { HUVEC } & \text { Human umbilical vein endothelial cells } \\ \text { IF } & \text { Immunofluorescence } \\ \text { IGFBP } & \text { Insulin-like growth factor-binding protein } \\ \text { IHC } & \text { Immunohistochemistry } \\ \text { LAD } & \text { Left anterior descending } \\ \text { MI } & \text { Myocardial infarction } \\ \text { NE } & \text { Norepinephrine } \\ \text { PKA } & \text { Protein kinase A } \\ \text { q-RT-PCR } & \text { Quantitative real-time PCR } \\ \alpha-S M A & \alpha \text {-smooth muscle actin } \\ \text { TGF- } \beta & \text { Transforming growth factor- } \beta \\ \text { TNF- } \alpha & \text { Tumor necrosis factor- } \alpha \\ \text { TNFR } & \text { Tumor necrosis factor receptor } \\ \text { TSS } & \text { Transcription start site } \\ \text { UCSC } & \text { University of California, Santa Cruz } \\ & \end{array}$


VWC von Willebrand factor type C

WISP-2 WNT1 inducible signaling pathway protein-2

\section{Introduction}

Ischemic heart disease, also known as coronary artery disease, is one of the leading causes of human morbidity and mortality (Moran et al. 2014). Following acute thrombosis of a coronary artery, ischemia of the myocardial region supplied by the artery ensues (Ambrose and Singh 2015). Unless immediate revascularization of the occluded artery is accomplished, ischemic necrosis of myocardial tissue occurs (Ambrose and Singh 2015). Based on the limited capacity of myocardial tissue to regenerate, tissue lost in ischemic necrosis is replaced by scar tissue by mechanisms similar to general wound healing (Eming et al. 2014). Release of chemoattractants from activated platelets and necrotic cells causes recruitment of inflammatory leucocytes (neutrophils and macrophages) that clear the injured area from dead cells and debris (Frangogiannis 2008). This inflammatory phase is subsequently followed by a proliferative phase with formation of granulation tissue that ultimately differentiates into a mature scar tissue (Ren et al. 2002; Frangogiannis 2008). Previous research has emphasized on ischemia-reperfusion injury and on unravelling novel mechanisms of cardioprotection in order to reduce myocardial necrosis (Altamirano et al. 2015). However, these efforts have yet not translated to new therapies. Thus, current treatment of acute myocardial infarction focuses on rapid revascularization of the occluded artery in order to rescue myocardial tissue from irreversible damage (Ibanez et al. 2018). Still, several pathophysiological mechanisms that operate during scar healing may ultimately have profound impact on ventricular remodeling and cardiac function, e.g. infarct area dilatation, removal of necrotic tissue by granulocytes and macrophages, neutrophil efferocytosis, progression of myofibroblasts into senescence and a senescence associated phenotype that keep on releasing a number of proinflammatory molecules (Prabhu and Frangogiannis 2016). Interestingly, matricellular CCN proteins have been reported to be involved in several of these mechanisms. CCN proteins are secreted proteins that play important roles in several aspects of wound healing, i.e. inflammation, angiogenesis and fibrosis (Jun and Lau 2011). The CCN protein family comprises 6 members typically characterized by having four conserved homology domains, i.e. an insulin-like growth factor-binding protein homology domain (IGFBP), a von Willebrand factor type C homology domain (VWC), a thrombospondin type 1 repeat (TSP) homology domain, and a C-terminal domain (CT) with a cystine knot motif (Bork 1993; Brigstock 1999). CCN5, formerly known as WNT1 inducible signaling pathway protein 2 (WISP-2), is a divergent member of the family in that it lacks the carboxyl-terminal cystine knot domain (Zhang et al. 1998). Indeed, CCN5 has been reported to have many opposite functions of CCN2 (Connective Tissue Growth Factor, CTGF). Whereas CCN2 have been implicated in myocardial fibrosis in heart failure of both ischemic and non-ischemic etiologies, mice with cardiac-restricted overexpression of CCN5 have been reported to exhibit attenuated myocardial fibrosis following chronic pressure overload of the heart, indicating an antagonistic role of CCN5 relative to that of CCN2 in the heart (Yoon et al. 2010). In this respect, previous studies revealed an inhibitory effect of CCN5 on proliferation and motility in smooth muscle cells (Lake et al. 2003; Mason et al. 2004) and fibroblasts (Xu et al. 2015), i.e. the opposite of the functions often ascribed to CCN2. In addition, $\mathrm{CCN} 5$ has been reported to inhibit transforming growth factor- $\beta$ (TGF- $\beta$ )-induced transdifferentiation of fibroblasts to myofibroblasts by diminishing expression of profibrotic mediators (Xu et al. 2015). While the distribution and regulation of $\mathrm{CCN} 2$ in the heart following myocardial infarction is well described, (Chen et al. 2000; Ahmed et al. 2004; Chuva de Sousa Lopes et al. 2004) that of CCN5 is largely unknown.

The aims of this study were to (1) investigate the cellular distribution and regulation of CCN5 in the heart following myocardial infarction (MI) and (2) elucidate the transcriptional regulation of CCN5 in cardiac fibroblasts and endothelial cells.

\section{Materials and methods}

\section{Cell culture}

Human embryonic kidney 293 cells (HEK293A) (R70507, Thermo Fisher Scientific, Waltham, USA), human embryonic lung fibroblasts (IMR-90) (ATCC CCL-186, LGC Standards, Germany) and primary murine cardiac fibroblasts (isolated from mouse hearts) were maintained in Dulbecco's modified Eagle's medium (DMEM) with high glucose (Gibco, Cat \# 41965-062, USA), supplemented with 10\% fetal bovine serum (FBS) (Gibco, Cat \# 16000044, USA) and $50 \mu \mathrm{g} / \mathrm{ml}$ gentamycin sulphate (Sanofi, Cat \# 453130, Norway). Human Umbilical Vein Endothelial Cells (HUVEC) (ATCC CRL-1730, LGC Standards, Germany) were maintained in Endothelial cell Basal Medium (EBM) (Lonza, Cat \# CC-3121, Switzerland), including the EGM SingleQuots growth supplements (Lonza, Cat \# CC-4133, Switzerland) and $50 \mu \mathrm{g} / \mathrm{ml}$ gentamycin sulphate.

\section{Plasmids}

For generation of recombinant adenovirus encoding luciferase-reporter under control of the CCN5 promoter, the 
pacAd5 shuttle vector (Anderson et al. 2000) was first engineered to incorporate a Gateway ${ }^{\mathrm{TM}}$ destination vector cassette (pGL4.10 from Promega, Madison, USA) upstream of the coding sequence of firefly luciferase. The human CCN5 promoter $(-1800 /+21)$ was custom-synthesized (ThermoFisherScientific) with flanking attB Gateway ${ }^{\mathrm{TM}}$ recombination sequences, and through standard Gateway ${ }^{\mathrm{TM}}$ ligation-independent cloning, transferred to the pacAd5 shuttle vector (Fig. SI-a). Truncated variants of the promoter $(-1191 /+21,-884 /+21$, and $-389 /+21)$ were generated by classical restriction enzyme subcloning techniques. A deletion of the putative cAMP response element (CRE): tgacctca (Fritah et al. 2006) of the $-398 /+21$ CCN5 promoter-reporter construct was custom-synthesized and also transferred to the adenoviral shuttle vector by Gatewaycloning. All synthesized constructs were verified by DNA sequencing analysis.

\section{Adenovirus preparations}

Infectious, replication-defective recombinant adenoviruses were generated in HEK293A cells following co-transfection of recombinant shuttle vector and the RAPAd viral backbone vector using Lipofectamin ${ }^{\mathrm{TM}}$ LTX Reagent with Plus ${ }^{\mathrm{TM}}$ Reagent (Invitrogen, Cat\# 15338100, USA). Recombinant viruses were subsequently amplified and purified with CaptoCore700 HiTrap ${ }^{\mathrm{TM}}$ (GE17-5481-51, GE Healthcare, Boston, USA) size-exclusion/anion exchange chromatography columns as described previously (Kaasboll et al. 2018), and titered with the Adeno-X rapid Titer kit from Clontech (Cat\# 631028, Takara Bio, USA) according to manufacturer's protocol. Adenoviruses were aliquoted and stored at $-80{ }^{\circ} \mathrm{C}$ until further use.

\section{CCN5 promoter-reporter assay}

IMR-90 cells, primary cardiac fibroblasts and HUVEC cells were seeded at densities of 10,000 cells/well (96well plates), 25,000 cells/well (24-well plates) and 15,000 cells/well (96-well plates) respectively, transduced with adenovirus encoding luciferase reporter under control of indicated fragment of CCN5 promoter at multiplicity of infection (MOI) of 1000. The cells were incubated overnight in full growth medium, serum-starved for 20-24 h, and subsequently stimulated with indicated concentrations of dexamethasone (Cat\# D1756, Sigma-Aldrich, USA), isoproterenol (Norges Apotekerforening, Oslo, Norway), norepinephrine (Norges Apotekerforening, Oslo, Norway), 8-Bromo-cAMP sodium salt (Cat\# 1140, TOCRIS, UK), recombinant rat TNF- $\alpha$ protein $(510-\mathrm{RT} / \mathrm{CF}$, R\&D SYSTEMS, USA), timolol maleate (PHR2593, Sigma-Aldrich), ICI-118,551 hydrochloride (I127, Sigma-Aldrich), atenolol
(A7655, Sigma-Aldrich), prazosin hydrochloride (P7791, Sigma-Aldrich), doxazosin mesylate (D9815, SigmaAldrich), TPCA-1 (Cat\# 2559, TOCRIS, UK) or vehicle for $24 \mathrm{~h}$. At the end of stimulation period, the medium was decanted and $100 \mu \mathrm{L}$ of ONE-Glo ${ }^{\mathrm{TM}}$ substrate / lysis reagent (Cat\# E6110, Promega), diluted 1:4 in $\mathrm{H}_{2} \mathrm{O}$, and was added to each well. The plates were subsequently incubated for $10 \mathrm{~min}$ before the lysates were transferred to black-walled plates and luciferase activity was determined by recording of luminescence signals with PolarStar Omega plate reader (BMG LABTECH, Germany).

\section{Isolation of RNA and quantitative real-time PCR (q-RT-PCR)}

Total RNA was isolated from myocardial tissue samples or cells by the RNeasy mini-kit (Cat\# 74004, QIAGEN, Hilden, Germany) according to the manufacturer's instructions. RNA was subsequently reverse-transcribed with the TaqMan Reverse Transcription Reagents Kit (Thermo Fisher Scientific) according to manufacturer's protocol, and the cDNA generated was utilized for real-time qPCR analyses using TaqMan ${ }^{\mathrm{TM}}$ Gene Expression Assays, Fast Advanced Master Mix and the StepOnePlus Real-Time PCR cycler (Thermo Fisher Scientific). mRNA levels are expressed as relative to $18 \mathrm{~S}$ rRNA. The TaqMan probes used are as follow: Human WISP2 (Assay ID: Hs01031984_m1), Human 18S (Assay ID: Hs99999901_S1), Mouse WISP2 (Assay ID: Mm00497471_m1), Mouse Rn18s (Assay ID: Mm03928990_g1).

\section{Immunofluorescence staining of IMR-90 cells and myocardial tissue sections}

IMR-90 cells were seeded in 24-well plates at a density of 10,000 cells/well on cover glass inserts. Following serumstarvation in $0.1 \%$ FBS overnight, the cells were stimulated with $100 \mathrm{nM}$ dexamethasone, $200 \mathrm{nM}$ isoproterenol, $1 \mathrm{mM}$ 8-Bromo-cAMP, $100 \mathrm{nM}$ ICI-118,551, or vehicle for $72 \mathrm{~h}$. Afterwards, the cells were fixed and permeabilized with $4 \%$ paraformaldehyde and $0.1 \%$ Triton-X100 in phosphate-buffered saline (PBS), respectively. 1\% BSA in PBS was used to block non-specific staining. Plates were then incubated overnight at $4{ }^{\circ} \mathrm{C}$ with anti-CCN5 antibody (abcam; Cat \# ab38317, Cambridge, UK) and subsequently with Alexa Fluor 594-conjugated goat anti-rabbit $\operatorname{IgG}(\mathrm{H}+\mathrm{L})$ (highly cross-adsorbed) as secondary antibody (Invitrogen; Cat \# A-11037) for $1 \mathrm{~h}$ at $37^{\circ} \mathrm{C}$ before nuclear staining with Hoechst 33258 (Thermo Fisher Scientific). Cover glasses were subsequently placed and fixed on glass slides and a Zeiss Axio Observer Inverted Microscope and ZEN 3.1 (ZEN lite, blue edition) software were used for image analyses. 
For double immunofluorescence staining of myocardial tissue, sections were blocked with PBS containing 5\% serum and subsequently incubated overnight at $4{ }^{\circ} \mathrm{C}$ with primary antibodies against CCN5 (abcam; Cat \# ab38317), and CD31 (ER-MP12; Thermo Fisher Scientific) or CD68 (ab201844; Abcam, Inc.). For co-staining of immunoreactive CCN5 and CD31, the sections were subsequently incubated with Alexa 594-labeled goat anti-rabbit IgG and Alexa 488-labelled goat anti-rat IgG (Thermo Fisher scientific). For co-staining of CCN5 and CD68, the sections were incubated with antiCCN5 IgG (abcam; Cat \# ab38317), and anti-CD68 IgGconjugated with Alexa 488, and subsequently incubated with secondary Alexa 594-labeled goat anti-rabbit IgG. Hoechst 33258 dye solution was used for nuclear staining.

\section{Western blot analysis of IMR-90 cells}

IMR-90 cells were seeded at a density of $9 \times 10^{5}$ cells/100 mm tissue culture dish in DMEM (Gibco, Cat \# 41965-062, USA) supplemented with $10 \%$ fetal bovine serum (FBS) and $50 \mu \mathrm{g} / \mathrm{ml}$ gentamycin sulphate and maintained in cell incubator for $24 \mathrm{~h}$ before medium change and serum-starvation in $0.1 \%$ FBS overnight. The cells were subsequently stimulated with $200 \mathrm{nM}$ isoproterenol, $100 \mathrm{nM}$ dexamethasone, or vehicle for $72 \mathrm{~h}$. Cell lysates were prepared in lysis buffer (1\% SDS in $10 \mathrm{mM}$ Tris- $\mathrm{HCl}, \mathrm{pH} 8.8$ ), sonicated, and centrifuged at $14,000 \times \mathrm{g}$ for $25 \mathrm{~min}$. The protein concentrations of the lysates were determined by the Pierce BCA assay kit (Thermo Fisher Scientific). For each sample, the same amount of protein was loaded and separated by SDS gel electrophoresis using 4-15\% TGX gradient gels (Bio-Rad) followed by transfer to a PVDF membrane using the Trans-Blot Turbo semidry blotting system (BioRad). The membrane was blocked in 5\% nonfat dry milk dissolved in Tris-buffered saline with Tween $20(20 \mathrm{mM}$ Tris- $\mathrm{HCl}, \mathrm{pH} 7.4,140 \mathrm{mM} \mathrm{NaCl}, 2.5 \mathrm{mM} \mathrm{KCl}$, and $0.1 \%$ Tween 20; all chemicals were analytical grade from Merck) for $1 \mathrm{~h}$ before probing with primary antibody in $5 \%$ nonfat dry milk dissolved in Tris-buffered saline containing $0.1 \%$ Tween 20 overnight at $4{ }^{\circ} \mathrm{C}$. The membrane was incubated successively with antibodies against CCN5 (LSBio; cat \# LS-C349158) and $\beta$-Actin (Cell Signaling; cat \# 4970S). Secondary antibody incubation was performed at room temperature for $1 \mathrm{~h}$ with HRP-linked anti-rabbit IgG (Cell Signaling; cat \# 7074). The membrane was finally incubated with SuperSignal West Femto Maximum Sensitivity Substrate (Thermo Fisher Scientific) and chemiluminescence signals were analyzed with the ChemiDoc imaging system (Bio-Rad). Densitometry of the immunoreactive bands was performed using the Image Lab 6.0.1 software.

\section{Animals}

All animal experiments were performed in accordance with the National Institutes of Health (NIH) Guide for the Care and Use of Laboratory Animals (8th edition, 2011) and were approved by the national board for laboratory animal research, the Norwegian Animal Research Authority (authorization no. 6288).

\section{Isolation of primary cardiac fibroblasts}

12-16 weeks old C57BL/6 female mice were anesthetized with gas anesthesia. Briefly, anesthesia was induced in an induction chamber providing ambient air with $3 \%$ isoflurane. During the subsequent procedures anesthesia was maintained by a face mask providing ambient air containing $1 \%$ isoflurane. Mice were subsequently euthanized by cervical dislocation and the hearts were rapidly excised, cannulated and perfused with collagenase type 2 (Worthington Biochemical Corp., NJ, USA), as described by O'Connell et al. (2007). Isolated fibroblasts were maintained in $10 \mathrm{~cm}$ culture dishes and allowed to adhere for $2 \mathrm{~h}$ before removal of unattached cells. The culture media was changed every second day until cell confluence. All experiments were carried out at passage 1-2.

\section{Experimentally-induced myocardial infarction (MI) and heart failure in mice}

Male and female rodents respond similarly with myocardial hypertrophy and left ventricular remodeling following experimental myocardial infarction although the magnitude of the changes may vary (Pfeffer et al. 1979; Wu et al. 2003; Cavasin et al. 2004). However, female mice are considerably less prone to myocardial rupture and thus, the potential bias caused by loss of animals in the experimental groups $(\mathrm{Wu}$ et al. 2003). Hence, in this study 12-16 weeks old female C57BL/6 mice were subjected to sham-operation $(n=3)$ or myocardial infarction $(\mathrm{MI})(\mathrm{n}=12)$ by ligation of the left anterior descending coronary artery (LAD) as described previously by Gao et al. (2010). Before the surgical procedure, anesthesia was induced by gas anesthesia (3\% isoflurane). Anesthesia was subsequently maintained by face mask providing a gas mixture of $2-3 \%$ isoflurane and $97-98 \%$ oxygen. Appropriate depth of anesthesia was controlled by absence of paw reflex. Buprenorphin $(0.1 \mathrm{mg} / \mathrm{kg}$ s.c.) was provided as analgesia immediately before and after the surgical procedure. The mice subjected to myocardial infarction were randomized to 4 groups ( $n=3$ in each group) to be 
euthanized 2, 7, 28, or 50 days after ligation of LAD. For analysis of myocardial mRNA, animals were euthanized 2 , 7,28 , or 50 days after induction of myocardial infarction. At the indicated end-points, the mice were anesthetized by gas anesthesia (3\% isoflurane) and subsequently euthanized by excision of the heart. Tissue samples from the infarcted part of the left ventricle and the non-ischemic myocardial region were harvested for extraction of RNA (days 2, 7 and 50 ) or IHC-analyses (28 days).

\section{Immunohistochemistry of myocardial tissue sections}

Myocardial tissue samples from MI- and sham-operated C57BL/6 mice were fixed in 4\% paraformaldehyde in phosphate-buffered saline for $1 \mathrm{~h}$, embedded in paraffin wax, and stored at $4{ }^{\circ} \mathrm{C}$. IHC analysis of myocardial sections $(6 \mu \mathrm{m})$ was performed as previously described (Ahmed et al. 2011), using rabbit polyclonal anti-mouse CCN5 (bs-5100R; Bioss Antibodies Inc., Woburn, USA) and rabbit monoclonal antimouse $\alpha$-smooth muscle actin ( $\alpha$-SMA) (ab124964; Abcam, Inc.). The avidin-biotin-peroxidase system (PK-6100, Vectastain Elite kit; Vector Laboratories, Inc., California, USA) was used for signal amplification. Omission of primary antibody was used as negative controls.

\section{Continuous infusion of isoproterenol in mice}

Myocardial samples from mice subjected to continuous infusion of isoproterenol were used from a previously reported study (Gravning et al. 2013). Briefly, 6 months old male C57BL/6 mice were randomized to continuous subcutaneous infusion of isoproterenol bitartrate $(50 \mathrm{mg} / \mathrm{kg}$ per day; Sigma-Aldrich) or vehicle for 14 days (vehicle, $n=9$ and isoproterenol infusion, $n=9$ ). Physical data from echocardiographic examination of these study groups have previously been reported (Gravning et al. 2013). Total RNA from myocardial biopsies from vehicle-infused $(n=6)$ and isoproterenol-infused $(n=5)$ mice were isolated and used for analysis of mRNA levels.

\section{Statistical analysis}

Data are shown as the mean \pm SEM $(n \geq 3$ independent experiments). Statistical analyses were performed using GraphPad Prism, version 6.0. Statistical analysis of differences between two groups was assessed by unpaired Student's two tailed t-test. Statistical analysis of differences among several experimental groups was performed by oneway ANOVA, followed by Dunnett's or Šidák's post hoc test as indicated in the figure legends when relevant. $p<0.05$ was considered to indicate statistically significant differences.

\section{Results}

\section{Diverging regulation of CCN2 and CCN5 mRNA after induction of myocardial infarction}

To decipher the regulatory patterns of CCN2 and CCN5 in tissue repair after myocardial infarction, the mRNA levels of CCN2 and CCN5 in the infarcted region and in non-ischemic myocardial tissue were analyzed at three different time points after induction of myocardial infarction in mice (Fig. 1a, b). CCN2 mRNA levels in the infarcted region increased rapidly following onset of ischemia and remained high during all the phases of wound healing, i.e. the inflammatory phase (day 2 post-MI), the proliferative phase (day 7 post-MI; granulation tissue) and maturation phase (day 50 post-MI; differentiated scar tissue) (Fig. 1a). In contrast to the CCN2 mRNA levels, the increase of CCN5 mRNA levels in the infarcted region was delayed and could first be detected during the proliferative phase of wound healing assayed at day 7 post-MI. CCN5 mRNA levels continued to be elevated in the differentiated scar (up to 50 days post-MI) (Fig. 1b). However, whereas CCN2 mRNA levels appear to display a transient increase in non-ischemic myocardial tissue consistent with previous findings (Ahmed et al. 2004), neither the alterations of CCN2 mRNA levels nor those of CCN5 in non-ischemic myocardial tissue were statistically significant compared with levels in sham-operated mice (Fig. 1a, b).

\section{Cellular distribution of CCN5 in the heart following myocardial infarction}

The finding of increased CCN5 mRNA levels in the healing wound following myocardial infarction indicates that the cells of the developing scar, such as endothelial cells, fibroblasts, or leukocytes may be the sources of CCN5. To further resolve this issue, tissue sections of hearts sampled from sham-operated mice, as well as from mice 4 weeks after induction of myocardial infarction, was used for immunohistochemical (IHC) and immunofluorescence (IF) staining. Immunohistochemical analysis of the distribution of CCN5 immunoreactivity in tissue sections from sham-operated animals revealed that CCN5 was largely confined to endothelial cells of capillaries and other microvessels (Fig. 2a). Similar distribution of CCN5 was observed in non-ischemic myocardial tissue of the mice subjected to myocardial infarction (Fig. 2b). In the developing scar tissue replacing the myocardial necrosis 4 weeks after induction of myocardial infarction, CCN5 immunoreactivity was observed in endothelial cells of capillaries and other microvessels, mononuclear leukocytes, and spindle-shaped fibroblast-like cells (Fig. 2c-e). CCN5 immunoreactivity was also observed in the muscular layer (smooth muscle cells of tunica media) of larger vessels 


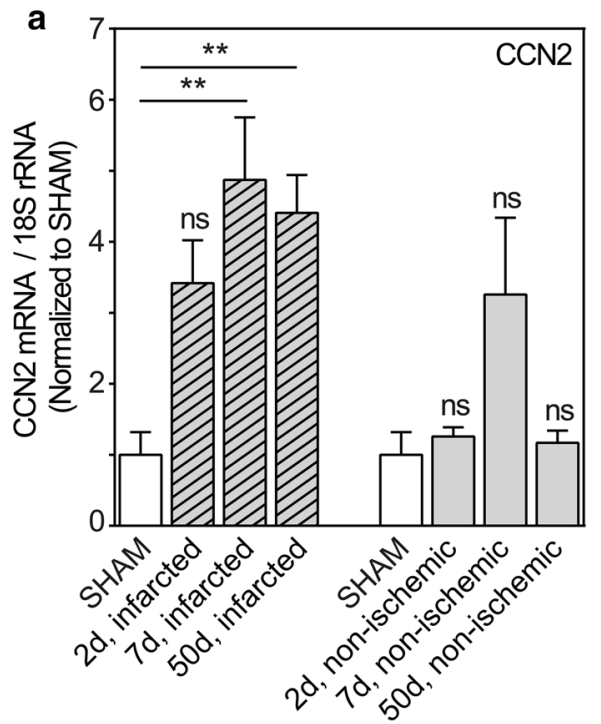

Fig. 1 Time course of CCN2 and CCN5 mRNA levels in infarcted and non-ischemic myocardial tissue after induction of experimental myocardial infarction in mice. Histogram demonstrating CCN2 (panel a) and CCN5 (panel b) mRNA levels relative to 18S rRNA (house-keeping) in infarcted region and in non-ischemic myocardial tissue, harvested 2, 7, and 50 days after permanent ligation of the left coronary artery and normalized to levels in myocardial tissue of sham-operated mice. A column (open column) representing levels in myocardial tissue of sham-operated mice has been included both in

(Fig. 2d) similar to the distribution of $\alpha$-smooth muscle actin $(\alpha-S M A)$ immunoreactivity (Fig. SI-b).

In order to determine the cellular origin of CCN5 in the tissue, IF double-staining of cardiac tissue sections from hearts sampled 4 weeks after induction of MI was performed with antibodies against CCN5 and either CD31 (marker of endothelial cells), or CD68 (marker of macrophages). First, immunofluorescence staining of CCN5 revealed that CCN5 immunoreactivity was prevailing in capillaries and other microvessels of both non-ischemic myocardial tissue and of the developing scar (Fig. 2f-h). Co-staining of CCN5 and CD31 immunoreactivities in the myocardial sections confirmed that endothelial cells were the prevailing cell type expressing CCN5 (Fig. 2i-k). Furthermore, cellular co-staining of CCN5 and CD68 also revealed CCN5 expression in macrophages of the developing scar tissue (Fig. 2l-n).

\section{Identification of human CCN5 promoter region}

To analyze the human CCN5 promoter region, the UCSC (University of California, Santa Cruz) Human Genome Browser Assembly (GRCh37/hg19, Feb. 2009) was used to locate the CCN5 gene within a chromosomal context. The promoter was identified as extending approximately 1500-1600 bp upstream of the transcription start site based

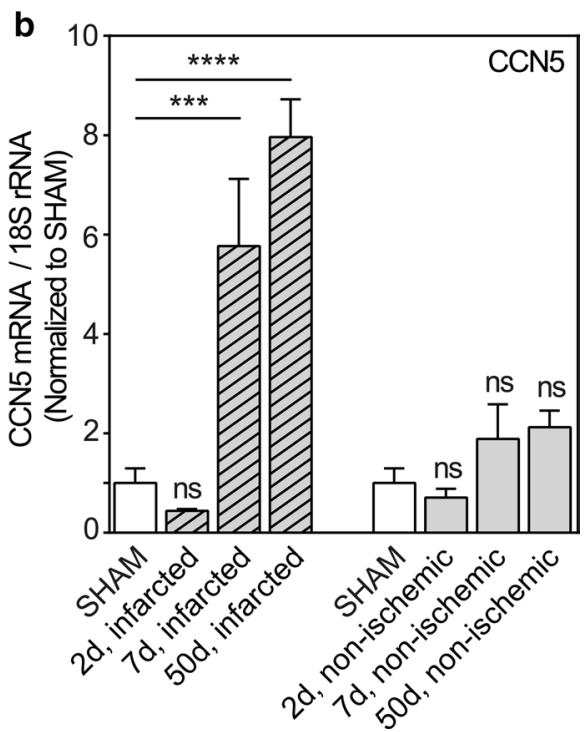

front of columns showing levels in the infarcted region and in front of columns demonstrating levels in non-ischemic myocardial tissue. mRNA levels were analyzed by real-time RT-PCR. Data are shown as the mean \pm SEM ( $n=3$ in each group). The data were subjected to statistical analyses by one-way ANOVA with Dunnett's post hoc test. Statistically significant alterations were indicated by $* * p<0.01$; $* * * p<0.001 ; * * * * p<0.0001$ versus sham-operated mice (SHAM); ns: indicates not statistically significant versus sham-operated mice (SHAM)

on the presence of epigenetic modifications of histone 3 (H3K27AC modifications), DNase I hypersensitivity clusters, (often found near active regulatory elements), and the clustering of ChIP-seq identified transcription factor binding elements (Fig. 3a). To ensure inclusion of all major regulatory elements, we used a fragment of $5^{\prime}$ untranslated CCN5 DNA up to $1800 \mathrm{bp}$ upstream of the transcription start site, thus yielding a construct of $-1800 /+21$ bp to be inserted in-frame with the reporter gene (Fig. 3a).

The Transfac database (TRANSFAC 2016) was hence used to predict potential transcription factor binding sites within the promoter region of CCN5. Figure $3 \mathrm{~b}$ shows a schematic of the $-1800 /+21$ CCN5 promoter-reporter construct with indication of putative transcription factor binding sites.

\section{The CCN5 promoter is responsive to glucocorticoids in IMR-90 cells, primary cardiac fibroblasts and HUVEC cells}

The promoter region of the CCN5 gene has previously been reported to contain a putative glucocorticoid response (enhancer) element (GRE) (5'-GGTACGTAC TGTTCC-3') and to respond to glucocorticoid stimulation 
(dexamethasone) in estrogen receptor alpha (ER $\alpha$ )-negative MDA-MB-231 breast cancer cells (Ferrand et al. 2012). The reported GRE in the promoter region of CCN5 is not a consensus GRE as originally proposed (Scheidereit et al. 1983). However, considerable degeneracy of the proposed consensus sequence has later been reported (Del Monaco et al. 1997). In order to confirm the involvement of the reported GRE of the CCN5 promoter to glucocorticoid stimulation, primary cardiac fibroblasts (cFBs) and human lung fibroblasts (IMR-90 cells) were transduced with recombinant adenovirus containing varying lengths of the CCN5 promoter $(-1800 /+21,-1191 /+21,-884 /+21$ and $-398 /+21)$ set to control the firefly luciferase (FLUC) reporter gene (Fig. 3c), and subsequently stimulated in the absence or presence of dexamethasone $(100 \mathrm{nM})$. Consistent with the report on CCN5 promoter responsiveness to glucocorticoids in MDA-MB-231 cells (Ferrand et al. 2012), the two longer promoter constructs $(-1800 /+21$ and $-1191 /+21)$ conferred reporter gene activity in response to dexamethasone in primary cFBs, IMR-90 cells, and human vein endothelial cells (HUVEC) (Figs. 3d, SI-c2, and SI-c3). In contrast, the more severely truncated promoter constructs $(-884 /+21$ and $-398 /+21$ ) lacking the GRE element, did not confer responsiveness to dexamethasone (Figs. 3d and SI-c2). Thus, the segment of the CCN5 promoter containing the described GRE is necessary for glucocorticoid induced activation of the CCN5-promoter also in these cells.

\section{CCN5 expression is induced by the $\beta$-adrenergic agonist isoproterenol in vitro and in vivo}

During the proliferation and maturation phases of wound healing following MI, when CCN5 is upregulated in the infarct region, neurohormonal activity is also often increased. Hence we investigated the effect of adrenergic stimulation on CCN5 expression in fibroblasts and endothelial cells, as they were identified to be major producers of CCN5 in the infarcted tissue (Fig. 2). As shown in Fig. 4a, isoproterenol, a nonselective $\beta$-adrenergic receptor agonist, stimulated CCN5 promoter activity in primary cFBs, IMR-90 cells, and HUVEC cells. Isoproterenol also increased CCN5 mRNA levels in primary cFBs, IMR-90 cells, and HUVEC cells following stimulation (Fig. 4b), and similarly in the hearts of mice subjected to isoproterenol infusion in vivo (Fig. 4c), the latter suggesting that $\beta$-adrenergic stimulation is also participating in regulation of $\mathrm{CCN} 5$ expression in vivo.

\section{The stimulatory effect of adrenergic agonists on the CCN5 promoter activity is dependent on $\beta_{2}$-adrenergic receptors}

In order to decipher what $\beta$-adrenergic receptor subtype is responsible for the responsiveness of the $\mathrm{CCN} 5$ promoter to $\beta$-adrenergic stimulation, cFBs, HUVEC cells, and IMR-90 cells were stimulated with norepinephrine in the presence or absence of the following adrenergic receptor-antagonists; timolol (a non-selective $\beta$-AR antagonist); ICI-118,551 (a selective $\beta_{2}$-AR antagonist); atenolol (a selective $\beta_{1^{-}}$ AR antagonist); doxazosin and prazosin (selective $\alpha_{1}$-AR antagonists), or incubated in the presence of the receptor antagonists alone. As shown in Figs. 4d and SI-d, norepinephrine-stimulated activation of the CCN5 promoter was not sensitive to atenolol, doxazosin or prazosin. However, the norepinephrine-stimulated activation of the CCN5-promoter was sensitive to both timolol and ICI-118,551, thus validating that the stimulatory effect of adrenergic agonists is dependent on $\beta$-receptors, and specifically $\beta_{2}$-receptors.

\section{The second messenger cAMP stimulates CCN5 gene expression in fibroblasts}

The major intracellular mediator generated by $\beta_{2^{-}}$ adrenergic receptor activation is cAMP. To investigate to what extent cAMP may convey stimulation of CCN5-promoter activity; we stimulated cFBs and IMR-90 cells with 8-bromo-cAMP (a brominated derivative of cAMP with cell membrane permeability and resistance to phosphodiesterases). Indeed, as shown in Fig. 5a, 8-bromo-cAMP induced CCN5 promoter activity in both IMR-90 cells and cFBs. In congruence with these findings, CCN5 mRNA levels were also upregulated following stimulation with 8-Bromo-cAMP (Fig. 5b) in cFBs and IMR-90 cells. To investigate whether the responsiveness of the CCN5 promoter to 8-Bromo-cAMP is mediated by protein kinase A (PKA) or exchange proteins directly activated by cAMP (EPACs), IMR-90 cells were stimulated with 8-BromocAMP in the presence or absence of H-89 (an inhibitor of protein kinase A (PKA)); 666-15 (a selective inhibitor of CREB); CE3F4 (a selective inhibitor of EPAC1); HJC 0350 (a selective inhibitor of EPAC2). As shown in Fig. 5c, 8-Bromo-cAMP-stimulated activation of the CCN5 promoter was sensitive to neither CE3F4 nor HJC 0350. However, the 8-Bromo-cAMP-stimulated activation of the CCN5-promoter was sensitive to both $\mathrm{H}-89$ and 66615. Thus, these results led us to hypothesize that cAMPinduced activation of the CCN5 promoter activity is conferred by the canonical cAMP response element (CRE) predicted to be present in the CCN5 promoter (Fritah et al. 2006). However, deletion of the CRE element from the CCN5 promoter did not abrogate 8-Bromo-cAMP-stimulated CCN5 transcriptional activity, indicating that this activity was mediated by a mechanism not dependent on the CRE element (Fig. 5d). 


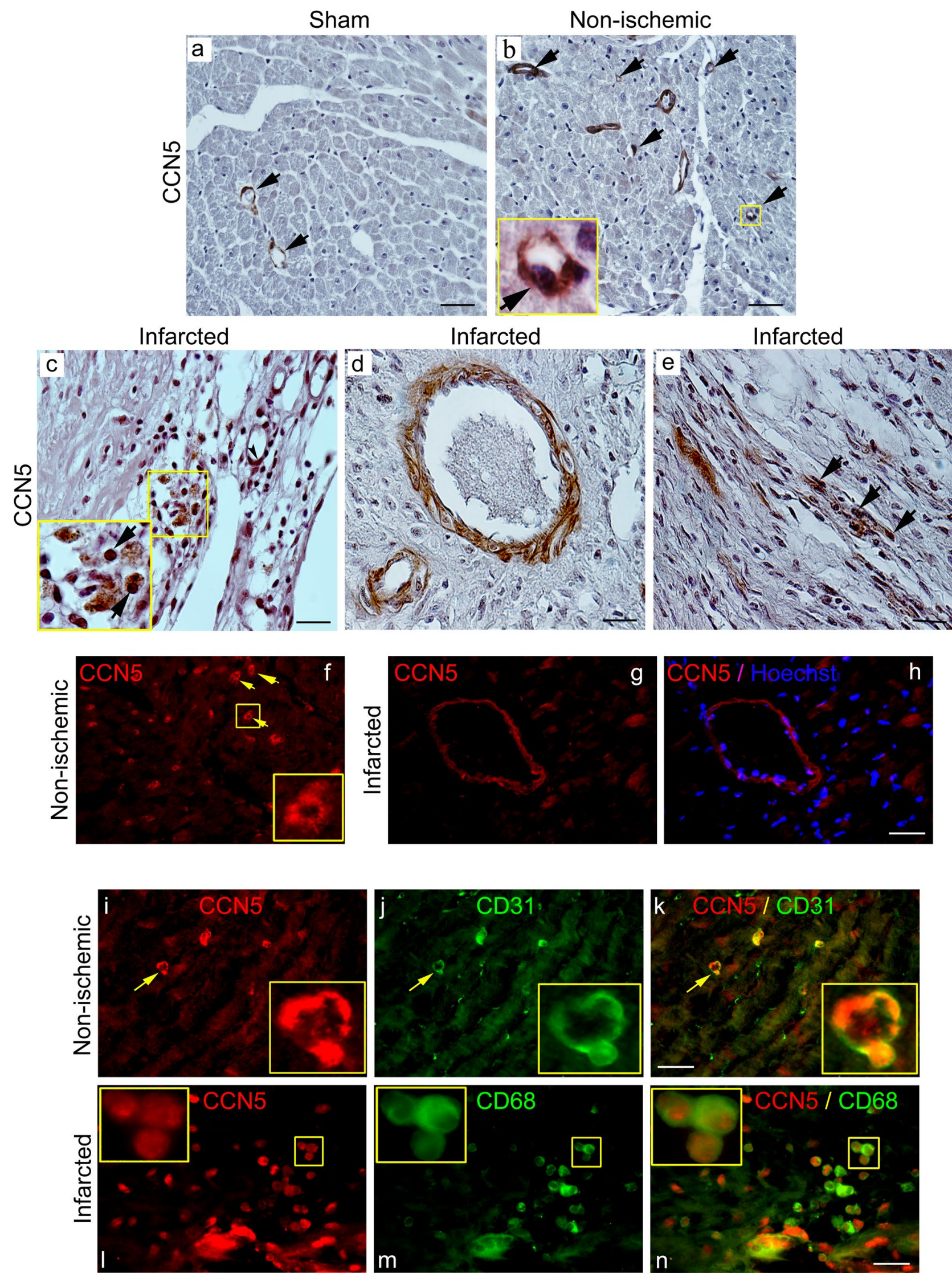


4Fig. 2 Immunohistochemical and immunocytochemical analysis of CCN5 immunoreactivity in myocardial tissue. The upper panels $(\mathbf{a}-\mathbf{e})$ are photomicrographs of immunohistochemistry of CCN5 immunoreactivity in myocardial tissue sections from a sham-operated mice, $\mathbf{b}$ non-ischemic region or $\mathbf{c}-\mathbf{e}$ infarct region of mice 4 weeks after permanent ligation of the left coronary artery and induction of myocardial infarction. The arrows in panels $\mathbf{a}$ and $\mathbf{b}$ indicate CCN5 immunoreactivity in endothelial cells of capillaries and small vessels. Panel $\mathbf{c}$ demonstrates CCN5 immunoreactivity in the differentiating scar tissue 4 weeks after myocardial infarction. The arrows point to immunostaining of mononuclear leukocytes. Panel d demonstrates immunostaining of muscular layer of a small artery. Panel e demonstrates CCN5 immunoreactivity in elongated, spindle-shaped cells likely to represent fibroblasts (arrowheads, panel e). Scale bar is $50 \mu \mathrm{M}$ for $\mathbf{a}$ and $\mathbf{b}$, and $20 \mu \mathrm{M}$ for $\mathbf{c}-\mathbf{e}$. Panels $\mathbf{f}-\mathbf{h}$ are photomicrographs of immunofluorescence analysis of CCN5 immunoreactivity in non-ischemic myocardial tissue or infarct region following ligation of the left coronary artery in mice. Arrowheads in panel $\mathbf{f}$ indicate immunostaining of capillaries in non-ischemic myocardial tissue (inlet demonstrates enlargement of immunoreactive capillary). Panel $\mathbf{g}$ and $\mathbf{h}$ demonstrate CCN5-positive artery in the infarct region with immunostaining of muscular layer (panel $\mathbf{h}$ shows overlay with Hoechst nuclear stain). Panels $\mathbf{i}-\mathbf{k}$ demonstrate double-staining of CCN5 and CD31 immunoreactivities in non-ischemic myocardial tissue. Panel $\mathbf{k}$ is an overlay of panels $\mathbf{i}$ and $\mathbf{j}$. Inlets demonstrate 100 -fold magnification of immunostaining of capillary indicated by arrowhead and confirming CCN5 immunoreactivity in CD31-positive endothelial cells. Panels $\mathbf{l}-\mathbf{n}$ demonstrate double-staining of CCN5 and CD68 reactivities in developing scar tissue 4 weeks after induction of myocardial infarction. Inlet (100-fold magnification in upper left corner of panels) demonstrates CCN5 immunoreactivity in CD68-positive macrophages (overlay in panel $\mathbf{n}$ ). Scale bar is $20 \mu \mathrm{M}$ for $\mathbf{f}-\mathbf{n}$. Photomicrographs of all panels are representative immunostaining of myocardial sections from 2 sham-operated mice or 2 mice subjected to myocardial infarction (three myocardial sections were subjected to each indicated immunostaining)

\section{CCN5 protein levels are increased following $\beta_{2}$-adrenergic stimulation in IMR-90 cells}

To investigate whether the $\beta_{2}$-adrenergic stimulation of CCN5 promoter activity and CCN5 gene expression also translated into increased protein expression, IMR-90 cells were stimulated in the presence or absence of isoproterenol with or without ICI-118,551 and analyzed for increase of CCN5 immunoreactivity by immunocytochemistry. As shown in Fig. 6a, stimulation of IMR-90 cells in the presence of dexamethasone, isoproterenol or 8-Bromo-cAMP all substantially enhanced CCN5 immunoreactivity. Furthermore, stimulation of the cells with isoproterenol in the presence of ICI-118,551 essentially abolished CCN5 immunostaining, corroborating the finding of $\beta_{2}$-adrenergic receptor-mediated activation of CCN5 transcription in IMR-90 cells. Consistent with the immunocytochemistry studies, Western blot analysis of IMR-90 cells stimulated with isoproterenol (200 nM) or dexamethasone $(100 \mathrm{nM})$ also demonstrated increased CCN5 levels (Fig. 6b).
TNF- $a$ inhibits expression of CCN5 in fibroblasts and endothelial cells

Although catecholamines were shown to increase the expression of CCN5 via $\beta$-adrenergic receptor activation, no increase of cardiac mRNA levels of CCN5 was observed in the early inflammatory phase following MI. During this period, the presence of inflammatory cytokines is known to be high (Nian et al. 2004). Hence, we hypothesized that expression of CCN5 might be repressed by an inflammatory cytokine during first days following MI. TNF- $\alpha$ is a proinflammatory cytokine elevated in the early phase of wound healing after myocardial infarction as well as in progression of ischemic heart failure and is associated with advancing fibrosis (Herskowitz et al. 1995; Nian et al. 2004; Kleinbongard et al. 2010). As shown in Fig. 7a TNF- $\alpha$ inhibited the CCN5 promoter activity in cFBs, IMR-90 cells, and HUVEC cells. Consistently, TNF- $\alpha$ also swiftly reduced CCN5 mRNA levels in both cFBs and IMR-90 cells (Fig. 7b). There are several predicted consensus NF- $\mathrm{BB}$ suppressor elements along the promoter of CCN5 (Fig. 7c-1). To investigate to what extent the repressive effect of TNF- $\alpha$ on CCN5 promoter activity was dependent on NF-KB signaling, IMR90 cells were transduced with recombinant adenovirus containing varying lengths of the CCN5 promoter $(-1800 /+21$, $-1191 /+21,-884 /+21$ and $-398 /+21$ ) set to control the firefly luciferase (FLUC) reporter gene (Fig. 7c-2), and subsequently stimulated with TNF- $\alpha$ in the presence or absence of TPCA-1 (a selective inhibitor of IKK-2 of the NF- $\mathrm{KB}$ pathway) or incubated with TPCA-1 alone. All promoter constructs $(-1800 /+21,-1191 /+21,-884 /+21$ and - 398/+21) conferred inhibition of reporter gene activity in response to TNF- $\alpha$. In addition, TPCA- 1 abolished the inhibitory effect of TNF- $\alpha$ at the CCN5 promoter variants except for the most severely truncated promoter construct $(-398 /+21)$ having only one NF- $\mathrm{KB}$ site (Fig. 7c-2). Thus, the repression of transcription from the CCN5 promoter appears to be mediated by IKK-2-dependent activity at the distal NF- $\mathrm{\kappa B}$ sites present from nucleotides -1800 to -398 of the $\mathrm{CCN} 5$ promoter.

\section{Discussion}

The present study reports data from investigations on transcriptional regulation and analysis of cellular distribution of CCN5 in the heart after myocardial infarction. The study discloses the novel findings that CCN5 is transcriptionally induced by catecholamines acting through $\beta_{2}$-adrenergic receptors on endothelial cells and cardiac fibroblasts and repressed by TNF- $\alpha$ through NF- $\mathrm{kB}$ suppressor elements, 
a

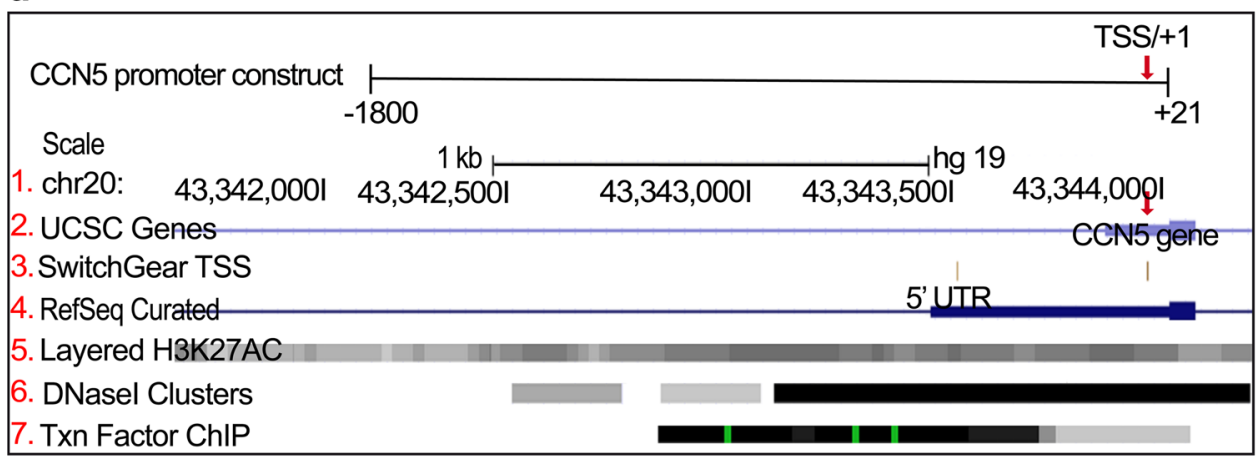

b

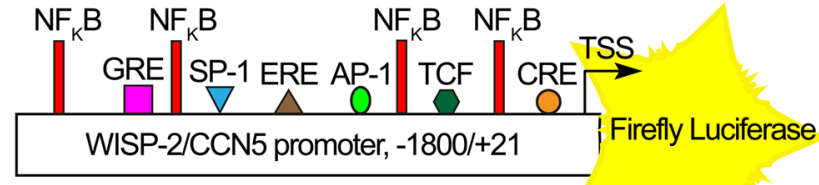

C

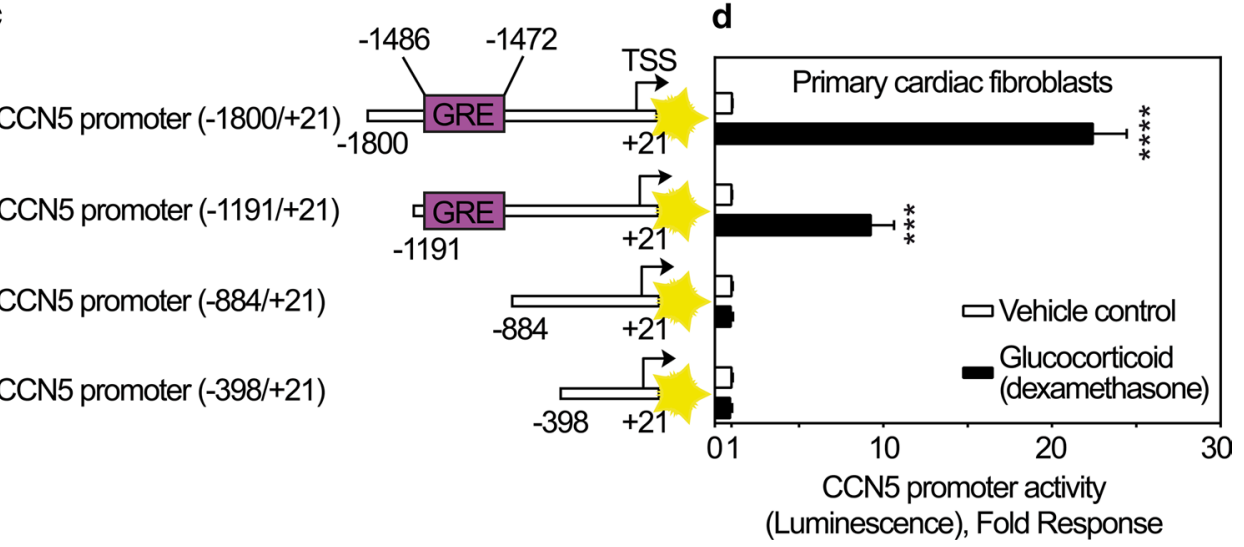

Fig. 3 Bioinformatic analysis and deletion studies of the promoter region of CCN5. a Schematic illustration of CCN5 promoter region $(-1800 /+21)$ upstream of the coding state of CCN5 gene. All tracks were set and displayed as dense. Red arrows demonstrate Transcription Start Site (TSS)/+1. (1) CCN5 gene is located on chromosome 20. The numbers are indicative of the base position with the genomic coordinates of the displayed region (gene promoter). (2) Homo sapiens WNT1 inducible signaling pathway protein 2 (WISP-2)/CCN5, mRNA, assembled by UCSC genome browser. (3) SwitchGear TSS: location of Transcription Start Sites (TSSs) throughout the human genome. Red arrow illustrates the chosen TSS/+ 1 with higher confidence score based on reported experimental evidence. (4) Transcript variants alignments of CCN5 according to RNA reference sequences (RefSeq) gene predictions from NCBI. (5) H3K27Ac mark: this involves acetylation of lysine 27 of the $\mathrm{H} 3$ histone protein. H3K27Ac is defined as an active enhancer mark often found near active regulatory elements. Overlayed H3K27Ac tracks show where modification of histone proteins is suggestive of enhancer and, to a lesser extent, other regulatory activity. (6) DNase I hypersensitive clusters (from ENCODE analysis) which are accessible chromatin zones, transcriptionally active and necessary for the binding of transcription factors. A gray box designates the degree of the hypersensitive region. The darkness is relative to the maximum signal strength observed in any of the reported 125 cell types. (7) Txn Factor ChIP: transcription factor (161 factors) binding motifs from a large collection of ChIP-seq experiments (chromatin immunoprecipitation followed by sequenc- ing) performed by the ENCODE Factorbook repository. Clusters are showing occupancy regions for each factor and motif sites within the regions. A gray box surrounds each peak cluster of transcription factor occupancy. The darkness is indicative of the maximum signal strength observed in any cell line contributing to the transcription factor occupancy. A green highlight, within a cluster indicates the highest scoring site of a Factorbook-identified established motif for the corresponding transcription factor. b Full length WISP-2/CCN5 promoter $(-1800 /+21)$ immediately preceding the transcription start site (TSS/+1) and coding sequence of firefly luciferase (FLUC) as reporter of CCN5 promoter activity. Consensus enhancer/suppressor elements in the promoter region of CCN5 are predicted and indicated according to the Transfac database. c Schematic demonstrating various deletions of the $-1800 /+21$ promoter construct with indications of the previously identified glucocorticoid response (enhancer) element (GRE). After infection of primary cardiac fibroblasts $\mathbf{d}$ with recombinant adenovirus encoding luciferase under control of the CCN5 promoter fragment with various deletions, the cells were stimulated with $100 \mathrm{nM}$ dexamethasone or vehicle for $24 \mathrm{~h}$ and assayed for luciferase activity. The results are presented as the mean \pm SEM ( $n=3$ independent experiments with two replicates per condition) of luciferase activity in primary cardiac fibroblasts stimulated in the absence or presence of dexamethasone. Statistical significance was assessed by unpaired Student's two tailed t-test. $*^{* *} p<0.001$ and $* * * * p<0.0001$ 
i.e. factors that are elevated following myocardial infarction and during ischemic heart failure. Further, high mRNA and protein levels of CCN5 were found in the granulation tissue and differentiating scar tissue after myocardial infarction. CCN5 immunoreactivity was predominantly confined to endothelial cells, fibroblast-like cells, and mononuclear leukocytes, similar to what has previously been reported for CCN2. However, induction of CCN5 was delayed compared with that of CCN2. Rising levels of CCN5 were first observed in the proliferative and maturation phases of wound healing suggesting disparate roles of CCN2 and CCN5.

$\mathrm{CCN} 2$ is considered an important mediator of myocardial fibrosis elevated in myocardial tissue in animal models as well as in patients with heart failure (Chen et al. 2000; Ahmed et al. 2004). As a diverging member of the CCN family, CCN5 is a particularly interesting molecule due to its reported ability to counteract the pro-fibrotic activity of CCN2 (Yoon et al. 2010). Yoon et al., showed that cardiac-restricted overexpression of CCN5 in genetically engineered mice reduced cardiac hypertrophy and fibrosis following pressure overload. The mechanisms of the opposing actions of CCN5 versus CCN2 is yet unknown, but could be related to the lack of the carboxyl-terminal cystine-knot domain present in 4-domain $\mathrm{CCN}$ proteins. Indeed, $\mathrm{CCN} 5$ with the cystine knot domain of $\mathrm{CCN} 2$ appended to its $\mathrm{C}$-terminal end was shown to attain properties similar to CCN2 in human skin fibroblasts (Xu et al. 2015). The regulation of CCN5 has also been found to differ from the regulation of CCN1, CCN2 and CCN3 in mouse embryos (Myers et al. 2012), indicating that CCN5 is subject to different regulatory mechanisms than the other $\mathrm{CCN}$ family members during embryonic development. The delayed increase of CCN5 mRNA levels relative to that of CCN2 mRNA levels in the infarcted region indicates that $\mathrm{CCN} 2$ and CCN5 may exert different actions during wound healing and tissue repair. Similar to CCN2, myocardial CCN1 and CCN4 also respond as immediate early genes and reach peak levels of expression during the inflammatory phase after onset of myocardial ischemia (Hilfiker-Kleiner et al. 2004; Colston et al. 2007; Jun et al. 2015).

In order to explore the factors that control CCN5 activity, we investigated transcriptional regulation from the CCN5 promoter. CCN5 has been previously reported to be transcriptionally induced by oestrogens and glucocorticoids in breast cancer cells (Banerjee et al. 2003; Fritah et al. 2006; Ferrand et al. 2012). The glucocorticoid response to CCN5 in MDA-MB-231 breast cancer cells was mapped to a glucocorticoid response element (GRE) in the promoter region of CCN5 (Ferrand et al. 2012). In this study, we also find that dexamethasone activates transcription from the CCN5 promoter in fibroblasts and that this response is lost in a truncated promoter lacking the GRE element. Similarly, it has previously been reported that an estrogen receptor element of the CCN5 promoter confers CCN5 transcription in response to estrogens (Fritah et al. 2006). However, in the same paper Fritah et al. (2006) also disclosed that the promoter region of CCN5 also contained consensus sequences for AP-1 enhancer elements, SP-1 elements, and CRE elements. Thus, neurohormonal activation subsequent to myocardial infarction and impairment of cardiac function may conceivably cause activation of transcription from the CCN5 promoter.

In this respect, elevation of myocardial CCN5 mRNA levels following chronic infusion of isoproterenol in mice is congruent with the finding of $\beta_{2}$-adrenergic receptor-mediated activation of transcription from the CCN5 promoter in cardiac fibroblasts and endothelial cells as reported in this study. Indeed, cardiac fibroblasts and endothelial cells have previously been found to predominantly express the $\beta_{2}$ adrenergic receptor subtype (Lau et al. 1980; Broeders et al. 2000; Kim et al. 2002). Although the mechanisms of CCN5mediated inhibition of fibrosis have not yet been resolved, the finding that CCN5 is induced by $\beta_{2}$-adrenergic receptor agonists is intriguing in view of a report showing that $\beta_{2^{-}}$ adrenergic receptor stimulation may promote collagen degradation and prevent fibrosis (Aranguiz-Urroz et al. 2011).

Cyclic-AMP, the major intracellular transmitter of $\beta$-adrenergic receptor activation, would be the principal candidate to confer catecholamine-stimulated transcription from the CCN5 promoter. Indeed, the cell permeable cyclic-AMP analog 8-bromo-cyclic-AMP, elicited robust transcription from the CCN5 promoter. Yet, although our data indicate that catecholamine-stimulated transcription from the CCN5 promoter is mediated via protein kinase $\mathrm{A}$, the downstream mechanism remains to be resolved. The fact that elimination of the putative CRE element by in situ mutagenesis did not abrogate 8-bromo-cyclic-AMP-mediated transcription from the CCN5 promoter suggests that cyclic-AMP-induced transcription of CCN5 may be conferred by a PKA-dependent mechanism that does not involve CREB and the CRE element. In this respect, it should be emphasized that both the PKA inhibitor (H-89) and the highly selective CREB inhibitor (666-15) only partially inhibited cyclic-AMP-stimulated transcription from the CCN5 promoter. Thus, cyclic-AMP/ PKA may cross-talk with other signaling pathways also involved in regulation of transcription from the CCN5 promoter. Indeed, PKA has been reported to catalyze phosphorylation of GSK-3 $\beta$ leading to TCF/LEF-mediated enhancement of transcription from the CCN5 promoter (McManus et al. 2005; Suzuki et al. 2008). Hence, non-CREB/CREdependent mechanisms for cyclic-AMP-mediated transcription from the CCN5 promoter appear to exist. Consistent with a cross-talk mechanism was also the observation that cyclic-AMP-induced elevation of CCN5 mRNA levels appeared to be a relatively slow response indicating that induction of CCN5 in this case may be due to a secondary 

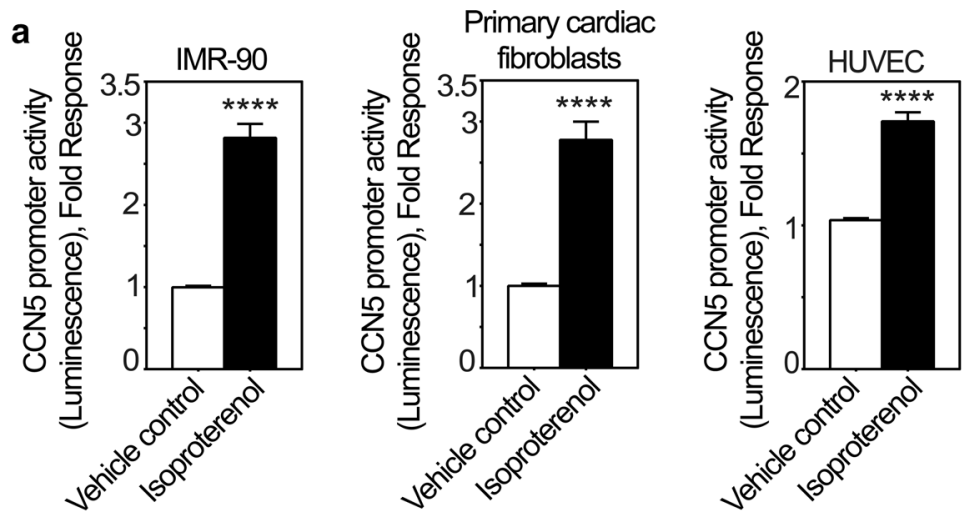

b
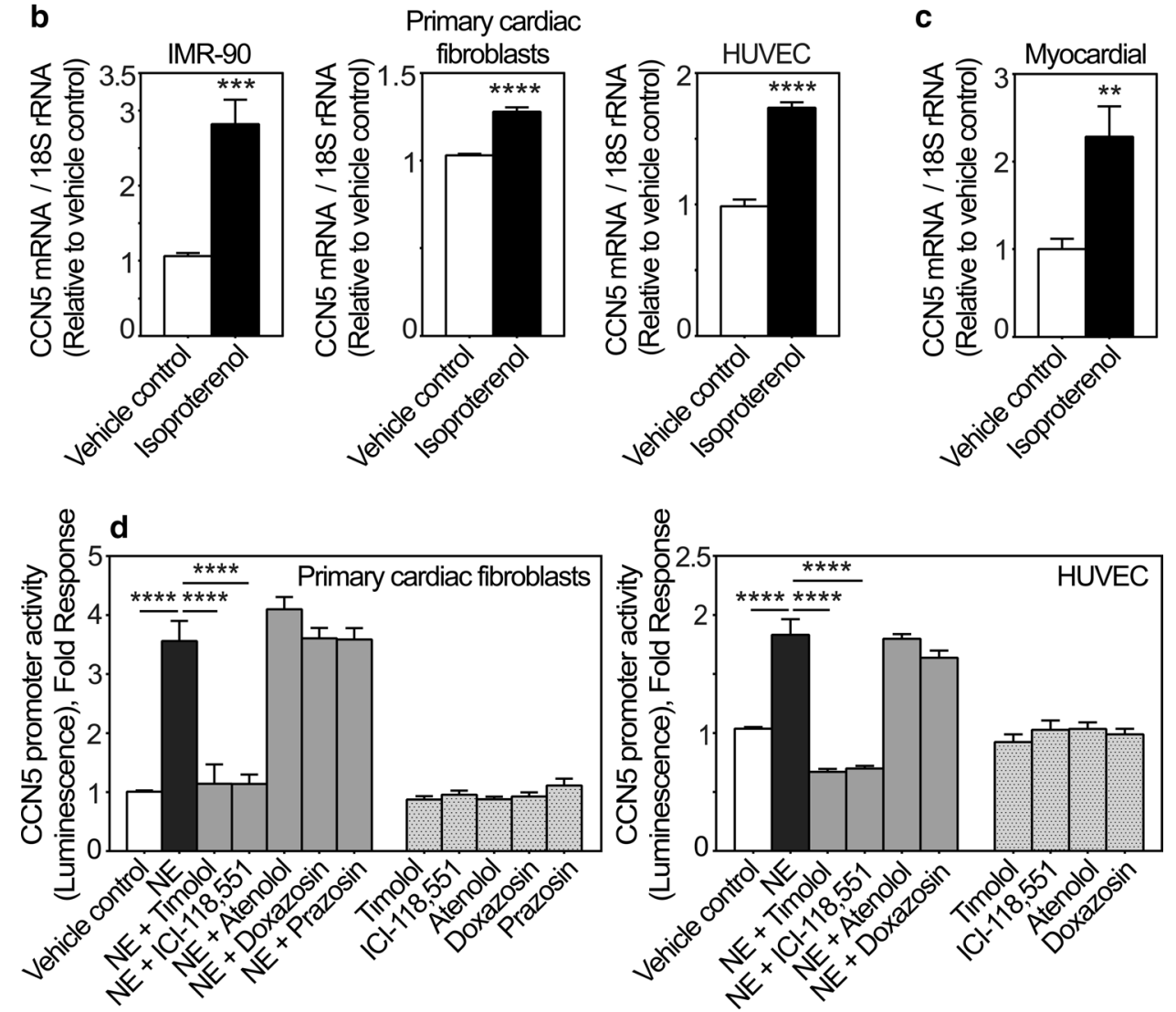

mechanism. A plausible explanation why cyclic-AMP-stimulated transcription of CCN5 could not be conferred by the CRE-element in the CCN5 promoter is still obscure. Conceivably, the context surrounding the CRE element may not favor stimulation of transcription from this element.

The mechanisms of the delayed induction of CCN5 relative to $\mathrm{CCN} 2$ following myocardial infarction has not yet been resolved. However, the finding in this study that TNF- $\alpha$ represses transcription from the $\mathrm{CCN} 5$ promoter via NF- $\mathrm{kB}-$ responsive elements may provide a plausible explanation for the delayed induction of CCN5 following myocardial infarction as myocardial TNF- $\alpha$ reaches peak levels within $24 \mathrm{~h}$ after myocardial infarction (Herskowitz et al. 1995; Nian et al. 2004).

The finding that the delayed increase of mRNA and protein levels of CCN5 was primarily observed in the region subjected to ischemic damage, prompted us to investigate the cellular distribution of CCN5 in this region. In normal hearts, immunoreactive $\mathrm{CCN} 5$ could primarily be discerned in endothelial cells and smooth muscle cells of muscular arteries. In the differentiating scar tissue, immunoreactive CCN5 was found in endothelial cells and fibroblast-like 
4Fig. 4 CCN5 transcriptional activity and mRNA levels are induced by catecholamines via $\beta_{2}$-adrenergic receptors. a Histogram demonstrating transcriptional activity of the CCN5 promoter after stimulation of IMR-90 cells, primary cardiac fibroblasts and HUVEC cells in the absence or presence of isoproterenol. Following infection with recombinant adenovirus encoding luciferase under control of the CCN5 promoter fragment, IMR-90 cells, primary cardiac fibroblasts and HUVEC cells were stimulated with $200 \mathrm{nM}$ isoproterenol or vehicle for $24 \mathrm{~h}$ and assayed for luciferase activity. The results were normalized to vehicle control and represent as the mean \pm SEM $(n \geq 3$ independent experiments each with three replicates per condition for IMR-90 and HUVEC cells and two replicates per condition for primary cardiac fibroblasts. b CCN5 mRNA levels in IMR-90 cells, primary cardiac fibroblasts and HUVEC cells stimulated in the absence or presence of isoproterenol. CCN5 mRNA levels were analyzed by real-time RT-PCR. Cells were seeded out and starved in $0.1 \%$ FBS for $24 \mathrm{~h}$ and subsequently, stimulated with $200 \mathrm{nM}$ isoproterenol or vehicle for $72 \mathrm{~h}$. The results were normalized to vehicle control and represent as the mean \pm SEM $(n=3$ independent experiments with two replicates per condition). c Myocardial CCN5 mRNA levels in mice subjected to continuous subcutaneous infusion of isoproterenol (50 mg/kg per day via micro-osmotic pumps) or vehicle for 14 days. Myocardial CCN5 mRNA levels were analyzed by real-time RTPCR. The results were normalized to levels in vehicle control group and presented as the mean \pm SEM $(n=5$ isoproterenol-infused and $\mathrm{n}=6$ vehicle control mice). Statistical significance was calculated by unpaired Student's two tailed t-test. ${ }^{*} p<0.01$, $* * * p<0.001$ and $* * * * p<0.0001$. Panel d shows histogram of the CCN5 promoter activity in primary cardiac fibroblasts and HUVEC cells transduced with recombinant adenovirus encoding luciferase under control of the CCN5 promoter and subsequently stimulated in the absence or presence of $20 \mu \mathrm{M}$ norepinephrine (NE) alone, or in combination with either $100 \mathrm{nM}$ timolol, $100 \mathrm{nM}$ ICI-118,551, $1 \mu \mathrm{M}$ atenolol, $10 \mathrm{nM}$ doxazosin, $10 \mu \mathrm{M}$ prazosin, or vehicle for $24 \mathrm{~h}$. The results were normalized to vehicle control and presented as the mean \pm SEM $(n \geq 3$ independent experiments each with two replicates (primary cardiac fibroblasts) or three replicates (HUVEC cells) per condition). Statistical significance was calculated by one-way ANOVA with Šidák's post hoc test. $* * * * p<0.0001$ versus NE group

cells as well as in macrophages. This cellular distribution is very similar to that previously observed for $\mathrm{CCN} 2$ and other 4-domain $\mathrm{CCN}$ proteins during formation of granulation tissue following myocardial necrosis (Ahmed et al. 2004; Colston et al. 2007; Jun et al. 2015) and may point to a role of CCN5 in inhibiting the other 4-domain CCN proteins. A former report showed that CCN5 may inhibit transdifferentiation of cardiac fibroblasts and endothelial cells to myofibroblasts in vitro (Jeong et al. 2016). The same report also provided evidence that CCN5 delivered to the heart by a recombinant adeno-associated virus vector caused apoptosis of activated myofibroblasts in the heart subjected to transverse aortic constriction and attenuated myocardial fibrosis. Endothelial cells are also critically involved in cardiac remodeling after myocardial infarction by actively secreting proteins such as extracellular matrix (ECM) proteins and pro-fibrotic factors (Segers et al. 2018) to regulate functions of neighboring cells. Interestingly, previous findings indicate that CCN5 inhibits endothelial-mesenchymal transition (EndMT) both in vivo and in vitro by downregulating fibroblast-associated genes and upregulating endothelial-associated markers, thus preventing transition of endothelial cells to myofibroblasts (Jeong et al. 2016). Scartissue macrophages may also be involved in the pathophysiology of myocardial remodeling, in particular if tissue injury persists, by releasing proinflammatory cytokines, growth factors, and pro-fibrotic factors (Nikolic-Paterson et al. 2014). Of note, CCN2 has been reported to promote inflammation and infiltration of macrophages in vitro and in vivo under inflammatory conditions (Charrier et al. 2014). Considering the various reports on converse actions of CCN5 and CCN2, it is conceivable that CCN5 secreted from fibroblasts, endothelial cells and macrophages may work in an autocrine/paracrine manner to modify the actions of CCN2 (and other four-domain CCN proteins) on fibroblasts and thereby inhibit fibrosis and contribute to resolution of the wound healing process. Based on evidence that CCN5 inhibits fibrosis (Yoon et al. 2010; Jeong et al. 2016; Huang et al. 2020), the delayed increase of CCN5 levels may function to curb excessive scar formation.

In conclusion, this study discloses the novel findings that transcription from the $\mathrm{CCN} 5$ promoter is stimulated by catecholamines via the $\beta_{2}$-adrenergic receptors on cardiac fibroblasts and endothelial cells and repressed by TNF- $\alpha$ through NF-KB suppressor elements in the promoter region of CCN5 (Fig. 8). The early inflammatory phase following myocardial 

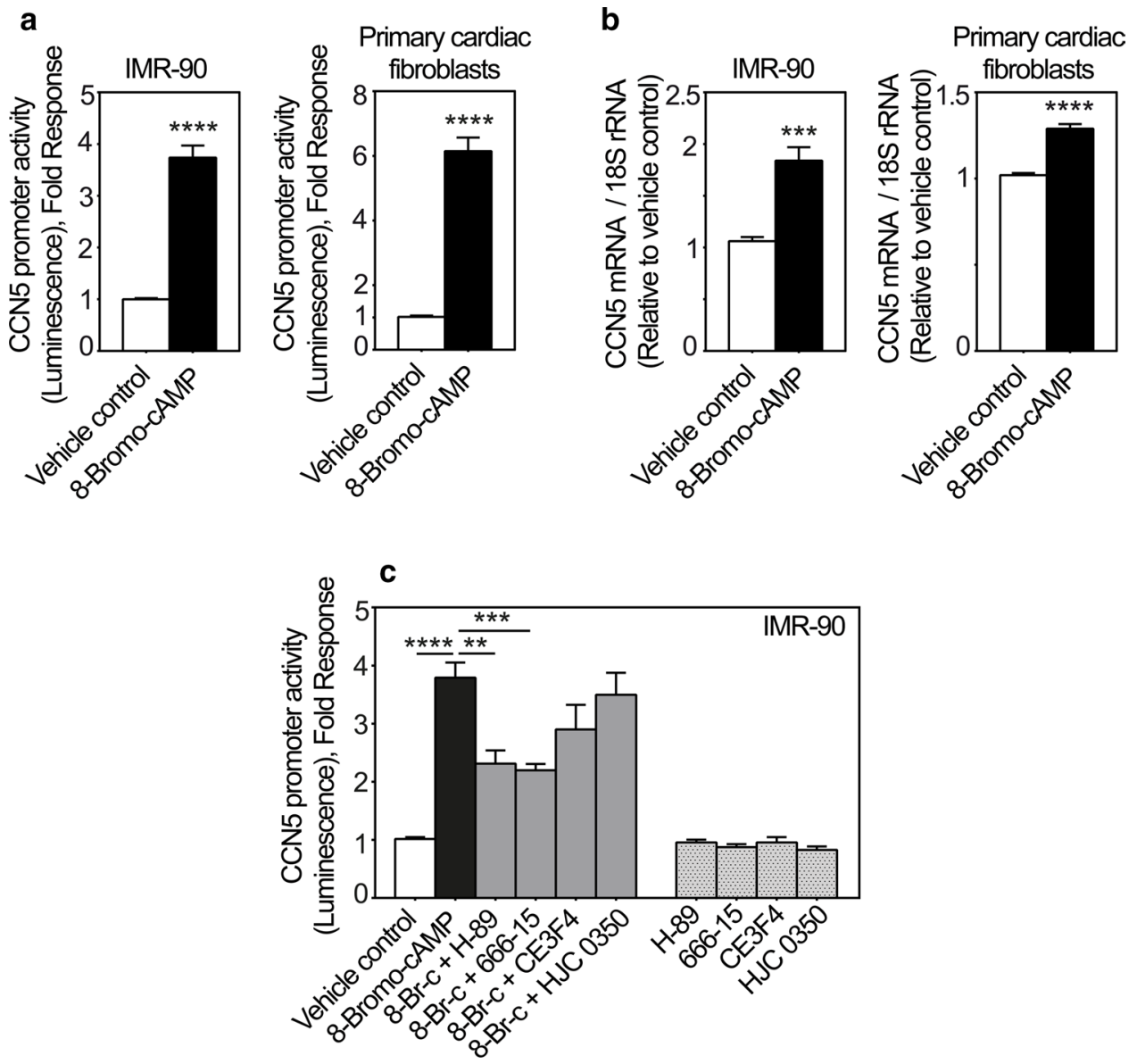

d

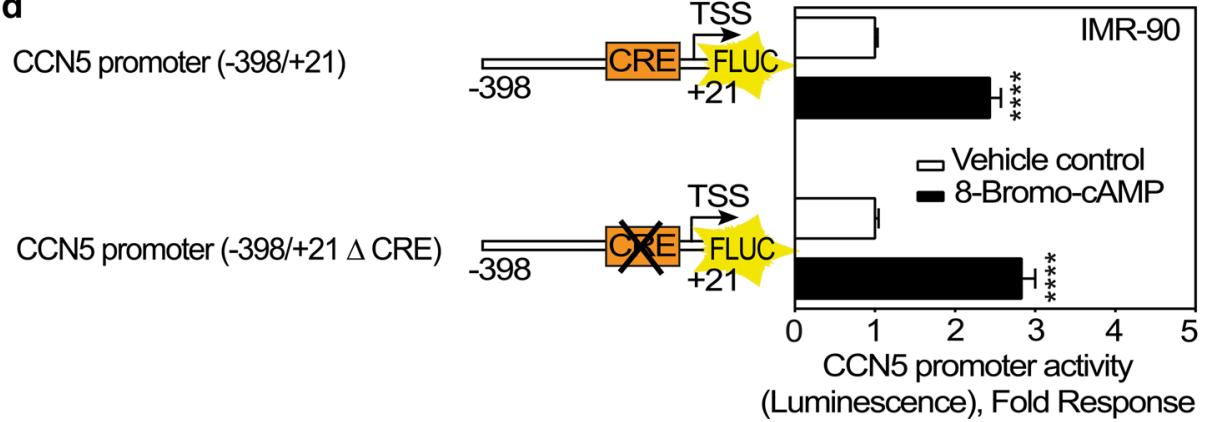

Fig. 5 CCN5 promoter activity is enhanced by 8-Bromo-cAMP. a Histogram demonstrating transcriptional activity of the CCN5 promoter following stimulation of IMR-90 cells or primary cardiac fibroblasts with 8-Bromo-cAMP. Briefly, the cells were infected with recombinant adenovirus encoding luciferase under control of the CCN5 promoter $(-1800 /+21)$. After transduction, cells were stimulated with $1 \mathrm{mM} 8$-Bromo-cAMP or vehicle for $24 \mathrm{~h}$ and subsequently assayed for luciferase activity. The results were normalized to vehicle control and presented as the mean \pm SEM $(n \geq 3$ independent experiments with each three replicates (IMR-90 cells) or two replicates (primary cardiac fibroblasts) per condition). b Histogram demonstrating CCN5 mRNA levels in IMR-90 cells and primary cardiac fibroblasts following stimulation with 8-Bromo-cAMP. Cells were seeded out and starved in $0.1 \%$ FBS for $24 \mathrm{~h}$ and then stimulated with $1 \mathrm{mM}$ 8-Bromo-cAMP or vehicle for $72 \mathrm{~h}$. mRNA levels were assayed by real-time RT-PCR. The results were normalized to vehicle control and presented as the mean \pm SEM $(n=3$ independent experiments each with two replicates per condition). c Histogram demonstrating transcriptional activity of the CCN5 promoter following stim- ulation of IMR-90 cells with $1 \mathrm{mM}$ 8-Bromo-cAMP (8-Br-c) alone or in combination with $100 \mathrm{nM} \mathrm{H}-89,100 \mathrm{nM} 666-15,100 \mathrm{nM}$ CE3F4, $100 \mathrm{nM}$ HJC 0350 , or vehicle for $24 \mathrm{~h}$. The results were normalized to vehicle control and represent the mean \pm SEM $(n=3$ independent experiments each with three replicates per condition). Statistical significance was calculated by one-way ANOVA with Sidák's post hoc test. $* * p<0.01, * * * p<0.001$ and $* * * * p<0.0001$ versus 8 -BromocAMP group. d Schematic and histogram demonstrating responsiveness of a CCN5 promoter fragment to 8-Bromo-cAMP in the absence or presence of CRE-element. Briefly, IMR-90 cells were infected with recombinant adenovirus encoding luciferase under control of - 398/+21 CCN5 promoter fragment with or without deletion of the CRE element. Following viral transduction, the cells were stimulated in the absence or presence of 8-Bromo-cAMP $(1 \mathrm{mM})$ for $24 \mathrm{~h}$ before recording of luciferase activities. The results were normalized to vehicle control and represent the mean \pm SEM $(n=3$ independent experiments each with three replicates per condition). Statistical significance was calculated by unpaired Student's two tailed t-test. $* * * * p<0.0001$ 
Fig. 6 Immunocytochemical and Western blot analyses of CCN5 in IMR-90 cells subjected to diverse exposures. a Panels are photomicrographs of IMR-90 cells subjected to immunofluorescence analysis of CCN5 immunoreactivity after stimulation of the cells in the absence or presence of $100 \mathrm{nM}$ glucocorticoid (dexamethasone), $1 \mathrm{mM}$ 8-Bromo-cAMP, $200 \mathrm{nM}$ isoproterenol, and $100 \mathrm{nM}$ ICI-118,551 for $72 \mathrm{~h}$. Nuclear DNA was stained with Hoechst 33258 (blue) Images are representative three independent experiments with 2 replicates per condition. More than 360 cells were analyzed per experimental condition. Scale bar is $50 \mu \mathrm{M}$. b Total cell lysates from IMR-90 cells stimulated in the absence or presence of isoproterenol (Iso; $200 \mathrm{nM}$ ) or dexamethasone (Dex; $100 \mathrm{nM}$ ) for $72 \mathrm{~h}$ were separated by SDS gel electrophoresis, transferred to PVDF membrane, and immunoblotted with antibodies against $\mathrm{CCN} 5$ and $\beta$-Actin. The photomicrograph demonstrates the immunoreactive bands and is representative of three independent experiments with 2 replicates per condition. The histogram shows densitometric analysis of CCN5 levels relative to $\beta$-actin (loading control) of the three independent experiments presented as mean \pm SEM.

Statistical significance was calculated by one-way ANOVA with Dunnett's post hoc test. ${ }^{*} p<0.05$ and $* * p<0.01$ versus unstimulated (Unstim) a
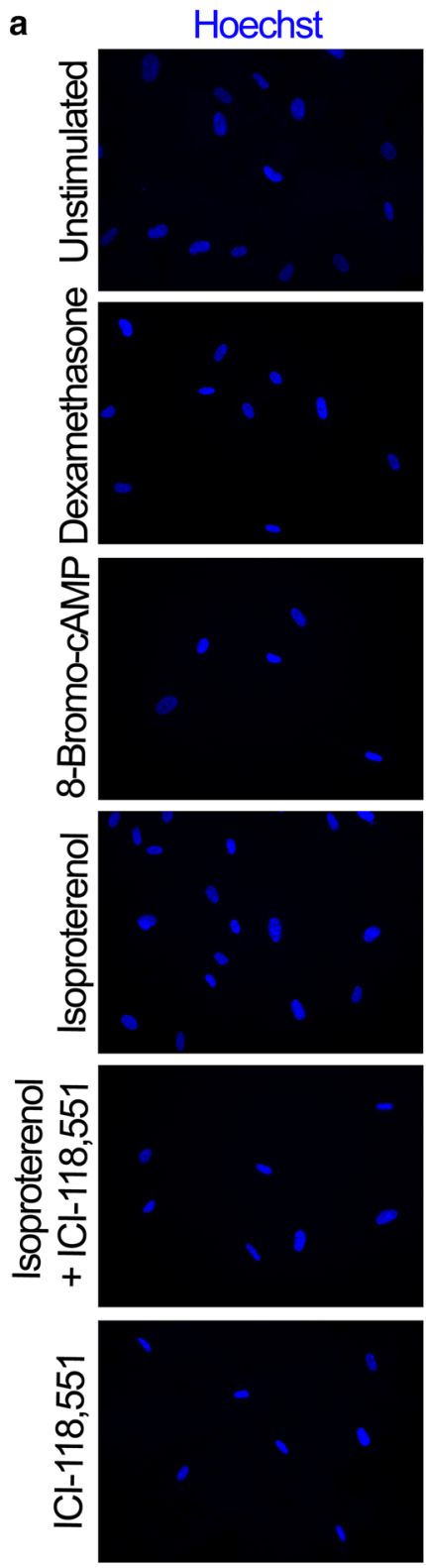

b

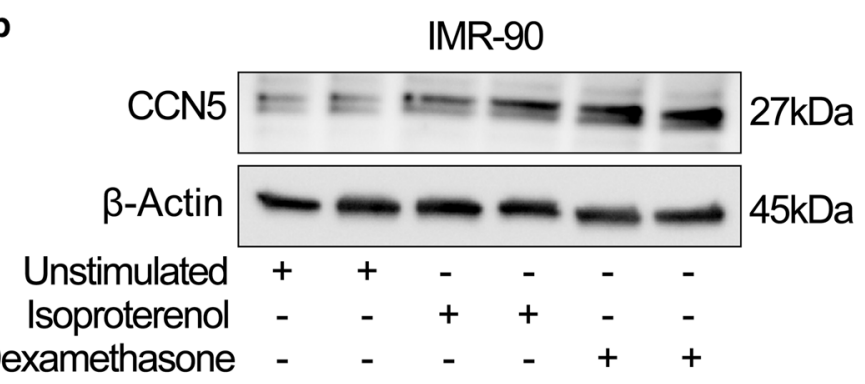

Merge
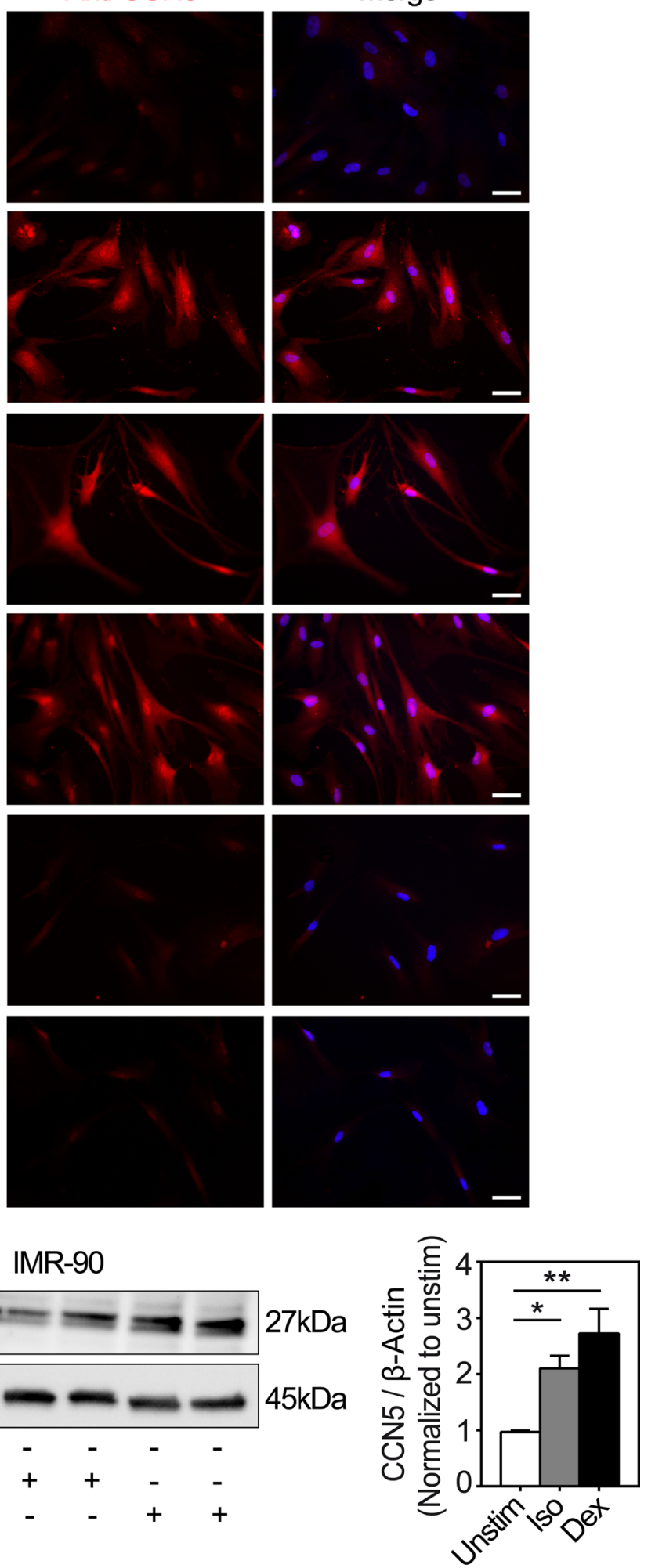

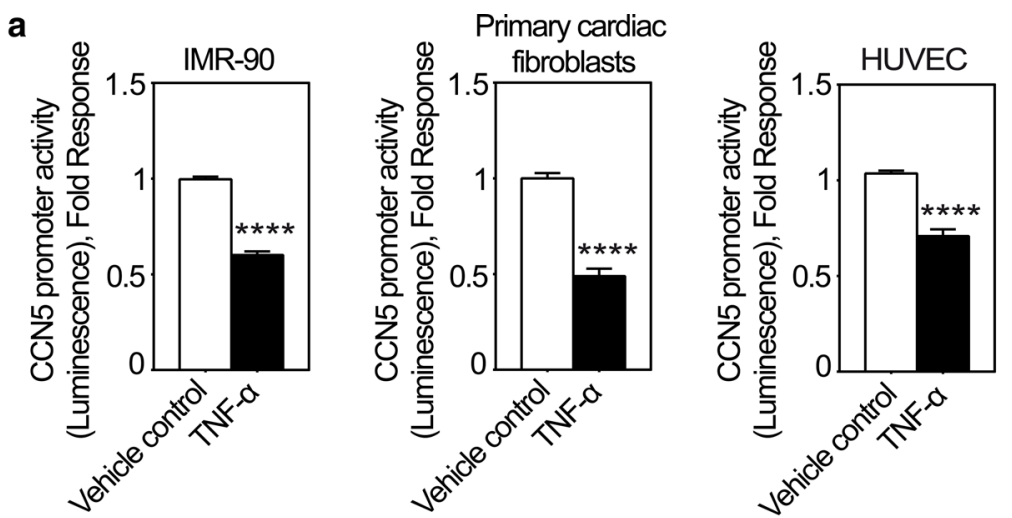

b
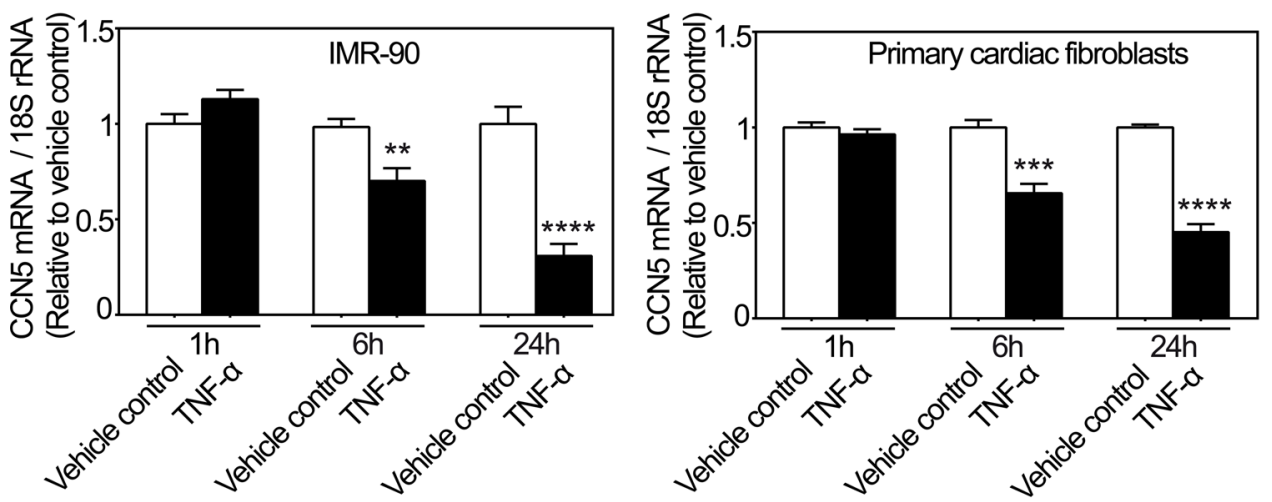

c-1

c-2

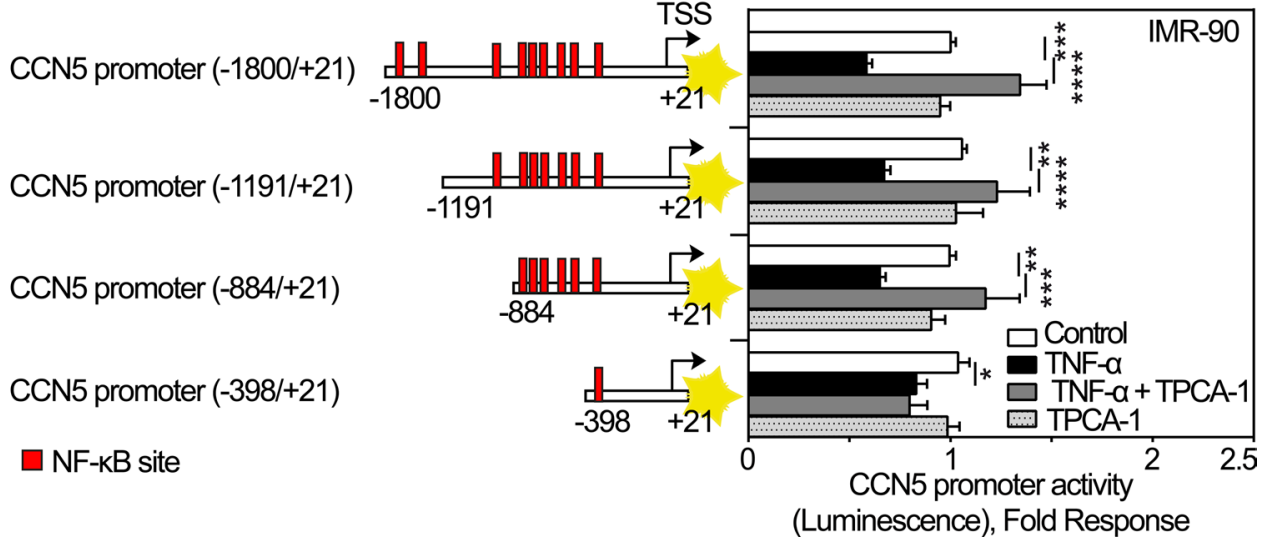

Fig. 7 CCN5 transcription is inhibited by TNF- $\alpha$. a Histogram demonstrating transcriptional activity of the CCN5 promoter after stimulation of IMR-90 cells, primary cardiac fibroblasts and HUVEC cells in the absence or presence of TNF- $\alpha$. Following infection with recombinant adenovirus encoding luciferase under control of the CCN5 promoter fragment, IMR-90 cells, primary cardiac fibroblasts and HUVEC cells were stimulated with TNF- $\alpha(100 \mathrm{ng} / \mathrm{ml})$ or vehicle for $24 \mathrm{~h}$ and assayed for luciferase activity. The results were normalized to vehicle control and represent as the mean \pm SEM $(n \geq 3$ independent experiments each with three replicates (IMR-90 and HUVEC cells) or two replicates (primary cardiac fibroblasts) per condition). b Histogram demonstrating CCN5 mRNA levels in IMR90 cells and primary cardiac fibroblasts following stimulation in the absence or presence of TNF- $\alpha$. The cells were seeded out and starved in $0.1 \%$ FBS for $24 \mathrm{~h}$ and subsequently, stimulated with $100 \mathrm{ng} / \mathrm{ml}$ TNF- $\alpha$ or vehicle for 1,6 and $24 \mathrm{~h}$ in both IMR-90 cells and primary cardiac fibroblasts. CCN5 mRNA levels were analyzed by real-time
RT-PCR. The results were normalized to vehicle control and presented as the mean \pm SEM $(n=3$ independent experiments each with two replicates per condition). Statistical significance was calculated by unpaired Student's two tailed t-test. ${ }^{* *} p<0.01$, *** $p<0.001$ and $* * * * p<0.0001$. c-1 Schematic demonstrating various CCN5 promoter fragments containing several putative NF- $\mathrm{KB}$ sites. c-2 After infection of IMR-90 cells with recombinant adenovirus encoding firefly luciferase under control of the CCN5 promoter fragment with various deletions, the cells were stimulated with $100 \mathrm{ng} / \mathrm{ml} \mathrm{TNF}-\alpha$ alone or in combination with $10 \mu \mathrm{M}$ TPCA- 1 or vehicle for $24 \mathrm{~h}$ and assayed for luciferase activity. The results were normalized to vehicle control and presented as the mean \pm SEM $(n \geq 3$ independent experiments each with three replicates per condition). Statistical significance was calculated by one-way ANOVA with Šidák's post hoc test. $* p<0.05, * * p<0.01, * * * p<0.001$ and $* * * * p<0.0001$ versus TNF- $\alpha$ group 
Fig. 8 Schematic model of transcriptional regulation of CCN5 in endothelial cells and fibroblasts of the heart. CCN5 promoter activities are conversely regulated by catecholamines and TNF- $\alpha$ in endothelial cells and fibroblasts

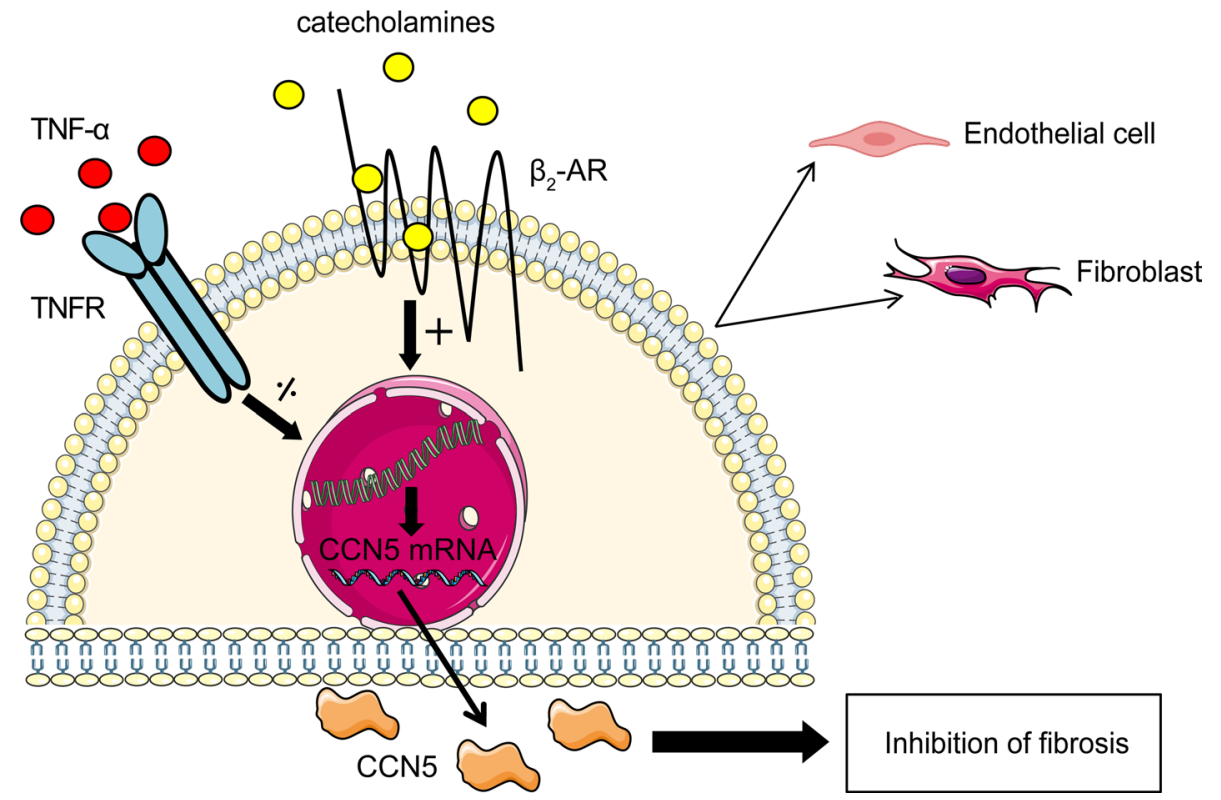

infarction with soaring levels of TNF- $\alpha$ may provide basis for the delayed increase of CCN5 relative to $\mathrm{CCN} 2$.

Supplementary Information The online version contains supplementary material available at https://doi.org/10.1007/s12079-021-00659-7.

Acknowledgements This work was supported by Grants from the Norwegian Council for Cardiovascular Research and from the South Eastern Norway Regional Health Authority [Grant Number HS $\varnothing$ 2016038] (fellowship to SZ).

Author contributions SZ, OJK and HA conceived and designed the project, interpreted all data and drafted the original manuscript; HA or OJK supervised all experiments; SZ and OJK designed plasmids and performed cloning; SZ constructed plasmids and adenoviruses, maintained HEK293A cells, IMR-90 cells, CFBs and HUVEC cells, designed and performed promoter-reporter assays in IMR-90 cells, CFBs and HUVEC cells and analyzed the data, q-RT-PCR of IMR-90 cells, CFBs and HUVEC cells and analyzed the data, immunofluorescence staining of IMR-90 cells and analyzed the data, Western blot of IMR-90 cells and analyzed the data; OJK performed experimentallyinduced MI surgery, q-RT-PCR of cardiac biopsies and analyzed the data; MSA performed q-RT-PCR of isoproterenol-infused samples, immunohistochemistry and immunofluorescence staining of myocardial tissue sections and analyzed the data; OJK, FSL, and EMVH performed isolation of primary cardiac fibroblasts; SZ, OJK, MSA, FSL, EMVH, VTM, and HA contributed to writing and critically revising the manuscript; HA acquired funding.

Funding Open access funding provided by University of Oslo (incl Oslo University Hospital).

Data availability The data underlying this article are available from the corresponding author on reasonable request.

\section{Declarations}

Conflict of interest The authors declare that they have no conflicts of interest.

Open Access This article is licensed under a Creative Commons Attribution 4.0 International License, which permits use, sharing, adaptation, distribution and reproduction in any medium or format, as long as you give appropriate credit to the original author(s) and the source, provide a link to the Creative Commons licence, and indicate if changes were made. The images or other third party material in this article are included in the article's Creative Commons licence, unless indicated otherwise in a credit line to the material. If material is not included in the article's Creative Commons licence and your intended use is not permitted by statutory regulation or exceeds the permitted use, you will need to obtain permission directly from the copyright holder. To view a copy of this licence, visit http://creativecommons.org/licenses/by/4.0/.

\section{References}

Ahmed MS, Oie E, Vinge LE et al (2004) Connective tissue growth factor-a novel mediator of angiotensin II-stimulated cardiac fibroblast activation in heart failure in rats. J Mol Cell Cardiol 36(3):393-404

Ahmed MS, Gravning J, Martinov VN et al (2011) Mechanisms of novel cardioprotective functions of CCN2/CTGF in myocardial ischemia-reperfusion injury. Am J Physiol Heart Circ Physiol 300(4):H1291-H1302

Altamirano F, Wang ZV, Hill JA (2015) Cardioprotection in ischaemiareperfusion injury: novel mechanisms and clinical translation. $\mathrm{J}$ Physiol 593(17):3773-3788

Ambrose JA, Singh M (2015) Pathophysiology of coronary artery disease leading to acute coronary syndromes. F1000Prime Rep 7:08 
Anderson RD, Haskell RE, Xia H et al (2000) A simple method for the rapid generation of recombinant adenovirus vectors. Gene Ther 7(12):1034-1038

Aranguiz-Urroz P, Canales J, Copaja M et al (2011) Beta(2)-adrenergic receptor regulates cardiac fibroblast autophagy and collagen degradation. Biochim Biophys Acta 1812(1):23-31

Banerjee S, Saxena N, Sengupta K et al (2003) WISP-2 gene in human breast cancer: estrogen and progesterone inducible expression and regulation of tumor cell proliferation. Neoplasia 5(1):63-73

Bork P (1993) The modular architecture of a new family of growthregulators related to connective-tissue growth-factor. FEBS Lett 327(2):125-130

Brigstock DR (1999) The connective tissue growth factor/cysteinerich 61/nephroblastoma overexpressed $(\mathrm{CCN})$ family. Endocr Rev 20(2):189-206

Broeders MAW, Doevendans PA, Bekkers BCAM et al (2000) Nebivolol: a third-generation beta-blocker that augments vascular nitric oxide release endothelial beta(2)-adrenergic receptor-mediated nitric oxide production. Circulation 102(6):677-684

Cavasin MA, Tao Z, Menon S et al (2004) Gender differences in cardiac function during early remodeling after acute myocardial infarction in mice. Life Sci 75(18):2181-2192

Charrier A, Chen R, Kemper S et al (2014) Regulation of pancreatic inflammation by connective tissue growth factor (CTGF/CCN2). Immunology 141(4):564-576

Chen MM, Lam A, Abraham JA et al (2000) CTGF expression is induced by TGF-beta in cardiac fibroblasts and cardiac myocytes: a potential role in heart fibrosis. J Mol Cell Cardiol 32(10): 1805-1819

Chuva de Sousa Lopes SM, Feijen A, Korving J et al (2004) Connective tissue growth factor expression and Smad signaling during mouse heart development and myocardial infarction. Dev Dyn 231(3):542-550

Colston JT, de la Rosa SD, Koehler M et al (2007) Wnt-induced secreted protein-1 is a prohypertrophic and profibrotic growth factor. Am J Physiol Heart Circ Physiol 293(3):H1839-H1846

Del Monaco M, Covello SP, Kennedy SH et al (1997) Identification of novel glucocorticoid-response elements in human elastin promoter and demonstration of nucleotide sequence specificity of the receptor binding. J Investig Dermatol 108(6):938-942

Eming SA, Martin P, Tomic-Canic M (2014) Wound repair and regeneration: mechanisms, signaling, and translation. Sci Transl Med 6(265):265sr266

Ferrand N, Stragier E, Redeuilh G et al (2012) Glucocorticoids induce CCN5/WISP-2 expression and attenuate invasion in oestrogen receptor-negative human breast cancer cells. Biochem J 447:71-79

Frangogiannis NG (2008) The immune system and cardiac repair. Pharmacol Res 58(2):88-111

Fritah A, Redeuilh G, Sabbah M (2006) Molecular cloning and characterization of the human WISP-2/CCN5 gene promoter reveal its upregulation by oestrogens. J Endocrinol 191(3):613-624

Gao E, Lei YH, Shang X et al (2010) A novel and efficient model of coronary artery ligation and myocardial infarction in the mouse. Circ Res 107(12):1445-1453

Gravning J, Ahmed MS, Qvigstad E et al (2013) Connective tissue growth factor/CCN2 attenuates beta-adrenergic receptor responsiveness and cardiotoxicity by induction of $\mathrm{G}$ proteincoupled receptor kinase-5 in cardiomyocytes. Mol Pharmacol 84(3):372-383

Herskowitz A, Choi S, Ansari AA et al (1995) Cytokine mRNA expression in postischemic/reperfused myocardium. Am J Pathol 146(2):419-428

Hilfiker-Kleiner D, Kaminski K, Kaminska A et al (2004) Regulation of proangiogenic factor $\mathrm{CCN} 1$ in cardiac muscle: impact of ischemia, pressure overload, and neurohumoral activation. Circulation 109(18):2227-2233

Huang A, Li H, Zeng C et al (2020) Endogenous CCN5 participates in angiotensin II/TGF-beta1 networking of cardiac fibrosis in high angiotensin II-induced hypertensive heart failure. Front Pharmacol 11:1235

Ibanez B, James S, Agewall S et al (2018) 2017 ESC guidelines for the management of acute myocardial infarction in patients presenting with ST-segment elevation: The Task Force for the management of acute myocardial infarction in patients presenting with STsegment elevation of the European Society of Cardiology (ESC). Eur Heart J 39(2):119-177

Jeong D, Lee MA, Li Y et al (2016) Matricellular protein CCN5 reverses established cardiac fibrosis. J Am Coll Cardiol 67(13):1556-1568

Jun JI, Lau LF (2011) Taking aim at the extracellular matrix: CCN proteins as emerging therapeutic targets. Nat Rev Drug Discov 10(12):945-963

Jun JI, Kim KH, Lau LF (2015) The matricellular protein CCN1 mediates neutrophil efferocytosis in cutaneous wound healing. Nat Commun 6: 7386

Kaasboll OJ, Gadicherla AK, Wang JH et al (2018) Connective tissue growth factor $(\mathrm{CCN} 2)$ is a matricellular preproprotein controlled by proteolytic activation. J Biol Chem 293(46):17953-17970

Kim J, Eckhart AD, Eguchi S et al (2002) Beta-adrenergic receptormediated DNA synthesis in cardiac fibroblasts is dependent on transactivation of the epidermal growth factor receptor and subsequent activation of extracellular signal-regulated kinases. J Biol Chem 277(35):32116-32123

Kleinbongard P, Heusch G, Schulz R (2010) TNF alpha in atherosclerosis, myocardial ischemia/reperfusion and heart failure. Pharmacol Ther 127(3):295-314

Lake AC, Bialik A, Walsh $\mathrm{K}$ et al (2003) CCN5 is a growth arrestspecific gene that regulates smooth muscle cell proliferation and motility. Am J Pathol 162(1):219-231

Lau YH, Robinson RB, Rosen MR et al (1980) Subclassification of beta-adrenergic receptors in cultured rat cardiac myoblasts and fibroblasts. Circ Res 47(1):41-48

Mason HR, Lake AC, Wubben JE et al (2004) The growth arrest-specific gene CCN5 is deficient in human leiomyomas and inhibits the proliferation and motility of cultured human uterine smooth muscle cells. Mol Hum Reprod 10(3):181-187

McManus EJ, Sakamoto K, Armit LJ et al (2005) Role that phosphorylation of GSK3 plays in insulin and Wnt signalling defined by knockin analysis. EMBO J 24(8):1571-1583

Moran AE, Forouzanfar MH, Roth GA et al (2014) Temporal trends in ischemic heart disease mortality in 21 world regions, 1980 to 2010: the Global Burden of Disease 2010 study. Circulation 129(14):1483-1492

Myers RB, Rwayitare K, Richey L et al (2012) CCN5 expression in mammals. III. Early embryonic mouse development. J Cell Commun Signal 6(4):217-223

Nian M, Lee P, Khaper N et al (2004) Inflammatory cytokines and postmyocardial infarction remodeling. Circ Res 94(12):1543-1553

Nikolic-Paterson DJ, Wang S, Lan HY (2014) Macrophages promote renal fibrosis through direct and indirect mechanisms. Kidney Int Suppl 4(1):34-38

O'Connell TD, Rodrigo MC, Simpson PC (2007) Isolation and culture of adult mouse cardiac myocytes. Methods Mol Biol 357:271-296

Pfeffer MA, Pfeffer JM, Fishbein MC et al (1979) Myocardial infarct size and ventricular function in rats. Circ Res 44(4):503-512

Prabhu SD, Frangogiannis NG (2016) The biological basis for cardiac repair after myocardial infarction: from inflammation to fibrosis. Circ Res 119(1):91-112 
Ren GF, Michael LH, Entman ML et al (2002) Morphological characteristics of the microvasculature in healing myocardial infarcts. J Histochem Cytochem 50(1):71-79

Scheidereit C, Geisse S, Westphal HM et al (1983) The glucocorticoid receptor binds to defined nucleotide sequences near the promoter of mouse mammary tumour virus. Nature 304(5928):749-752

Segers VFM, Brutsaert DL, De Keulenaer GW (2018) Cardiac remodeling: endothelial cells have more to say than just NO. Front Physiol 9:382

Suzuki A, Ozono K, Kubota T et al (2008) PTH/cAMP/PKA signaling facilitates canonical Wnt signaling via inactivation of glycogen synthase kinase-3beta in osteoblastic Saos-2 cells. J Cell Biochem 104(1):304-317

TRANSFAC (2016) Wolfenbüttel, Germany. TRANSFAC taken over by geneXplain. http://www.genexplain.com/transfac/. Accessed 07 Jul 2016
Wu JC, Nasseri BA, Bloch KD et al (2003) Influence of sex on ventricular remodeling after myocardial infarction in mice. J Am Soc Echocardiogr 16(11):1158-1162

$\mathrm{Xu} \mathrm{H}$, Li P, Liu M et al (2015) CCN2 and CCN5 exerts opposing effect on fibroblast proliferation and transdifferentiation induced by TGF-beta. Clin Exp Pharmacol Physiol 42(11):1207-1219

Yoon PO, Lee MA, Cha $\mathrm{H}$ et al (2010) The opposing effects of CCN2 and CCN5 on the development of cardiac hypertrophy and fibrosis. J Mol Cell Cardiol 49(2):294-303

Zhang R, Averboukh L, Zhu W et al (1998) Identification of rCop-1, a new member of the $\mathrm{CCN}$ protein family, as a negative regulator for cell transformation. Mol Cell Biol 18(10):6131-6141

Publisher's Note Springer Nature remains neutral with regard to jurisdictional claims in published maps and institutional affiliations. 